Revista lus et Praxis, Año 17, No 1, 2011, pp. 3 - 30

ISSN 0717 - 2877

Universidad de Talca - Facultad de Ciencias Jurídicas y Sociales

"La interpretación jurisprudencial extensiva a los

verbos rectores de la lex Aquilia de damno"

Cristián Aedo Barrena

\title{
LA INTERPRETACIÓN JURISPRUDENCIAL EXTENSIVA A LOS VERBOS RECTORES DE LA LEX AQUILIA DE DAMNO*
}

\author{
THE JURISPRUDENTIAL EXTENSIVE INTERPRETATION TO \\ THE GOVERNING VERB OF THE LEX AQUILIA OF DAMNO
}

Cristián Aedo Barrena*

\section{RESUMEN}

El presente artículo asume la premisa, sustentada por la doctrina romanística mayoritaria, de que el delito de damnum, en otros términos, el otorgamiento de la actio directa emanada de la lex Aquilia, suponía cumplir, tanto para el capítulo primero, como para el tercero, el principio corpore corpori, es decir, que se exigía un inmediato contacto físico entre el autor del daño, sobre el cuerpo de la cosa dañada. Desde este punto de vista, el artículo explora los mecanismos de ampliación jurisprudencial de los verbos rectores del capítulo primero y tercero. En relación con el capítulo primero, se analiza el origen, evolución y admisión de la famosa distinción de Celso, entre occidere y causam mortis praestare. Según esta fórmula, siempre que se cumpliese con el principio corpore corpori en el resultado de muerte, procedía el otorgamiento de una acción directa. En cambio, en las hipótesis de omisiones que conducían a un resultado de muerte, que en la fórmula de Celso se traduce en la expresión causam mortis praestare (dar ocasión

de muerte), era procedente la acción decretal. El problema es que, como se analiza en el texto, la fórmula fue perfilada recién en el período clásico, con un antecedente en Ofilio y, una vez elaborada por Celso, no fue seguida en todos los casos por juristas contemporáneos o posteriores a él, lo que supone preguntarse las razones que llevaron a algunos juristas a otorgar una acción directa en los casos de conductas omisivas. Finalmente, en relación con el capítulo tercero, el artículo se detiene fundamentalmente en la ampliación desde la interpretación de rumpere por corrumpere, tanto en los casos de causalidad mediata, como en aquellos en los que la cosa no era destruida, pero perdía funcionalidad para el dueño.

\section{ABSTRACT}

This article assumes the premise, supported by doctrine Romance majority, that the crime of damnum, in other words, the granting of direct actio issued by the lex Aquilia, supposed meet for both the first chapter, and for the third, corpore corpori principle, that required an immediate contact between the author's physical damage in the body of the item damaged. From this point of view, the article explores the jurisprudential extension mechanisms governing verb first

\footnotetext{
*Trabajo recibido el 24 de enero y aprobado el 8 de abril de 2011.

** Abogado; Doctor en Derecho por la Universidad de Deusto; Profesor de Derecho Civil de la Universidad Católica del Norte, Antofagasta. Correo electrónico: caedo@ucn.cl.
} 
and third chapter. In relation to the first chapter, he examines the origin, evolution and admission Celso's famous distinction between occidere and causam mortis praestare. According to this formula, provided that it complied with the principle corpore corpori the outcome of death, came the award of direct action. In contrast, in the cases of omissions that led to a fatal outcome, that Celso's

formula means causam mortis praestare (give time of death), it was appropriate action decretal. The problem is that, as discussed in the text, the formula was recently profiled in the classical period, with a background in Ofilio and once drafted

by Celso, was not followed in all cases contemporary jurists or after him, which

is asking the reasons that led some jurists to give a direct action cases of acts of omission. Finally, in relation to chapter third, the article essentially stops the extension from rumpere interpretation by corrumpere both cases mediate causation, as in those in which the thing was not destroyed, but lost functionality to the owner.

PALABRAS CLAVE

Actio Legis, Damnum Corpore Corpori, Acciones in Factum-Actio Util; Verbos de la Ley

KEY WORDS

Actio Legis, Damnum Corpore Corpori, Actions in Factum, Actio Util, Legitimization, Verbs of the Law

\section{INTRODUCCIÓN: EL PRINCIPIO CORPORE CORPORI}

La lex Aquilia se caracterizó por la tipicidad de las figuras sancionadas y, como consecuencia, su carácter original no permitió la resolución de todos los casos que suponían la existencia de daños para el propietario ${ }^{1}$. Ello por cuanto, se piensa, la acción directa en la lex Aquilia tenía lugar cuando alguno había causado a otro un daño material con su propio cuerpo, respondiendo el causante con arreglo al principio denominado damnum corpore datum, es decir, que la aplicación literal de los verbos occidere, urere, frangere, rumpere, contenidos en los capítulos primero y tercero de la ley, suponían que el daño fuera ocasionado (conducta comisiva), a través de un inmediato contacto físico violento entre sujeto agente y sujeto pasivo. Como explica Arangio Ruiz: "El daño previsto por la lex Aquilia es solamente el causado corpore corpori, es decir, el producido con el esfuerzo muscular del delincuente a la cosa considerada en su estructura física. La sanción de la ley no tiene lugar, en consecuencia, por falta de daño corpore, si se encierra el ganado en un establo para hacerlo morir de

\footnotetext{
1 Pugliese, Giovanni, Istituzioni di Diritto Romano, Giappichelli, $3^{a}$ edición, Turín, 1991, p. 605, quien sostiene: "In un primo momento prevalse un'interpretazione letterale e restrittiva del testo della lex, per cui si esclusero dal suo ámbito di applicazione tutte quelle condotte che non consistessero in un facere positivo e concreto (così si escluse per esempio l'applicabilità dell'actio ex lege Aquilia per dani conseguenti ad un contegno meramente omissivo), e si richiese che il danno avvenisse mediante contatto diretto fra la persona del dannegiante e la cosa e consistesse nella distribuzione o nel deterioramento materiale della cosa stessa (damnum corpore corpori datum)".
} 
hambre, o si se persuade a un esclavo de que suba a un árbol, ocasionándole de esa manera la caída y muerte (Gayo, III, 219)"2.

En efecto, la acción tenía lugar cuando el daño se había causado con su propio cuerpo (damnum corpore datum). Si se había hecho de otro modo, procedía la acción pretoria, como cuando, por ejemplo, se dejaba morir de hambre a un esclavo o si se convencía a un esclavo ajeno para que se subiera a un árbol o bajara a un pozo y al hacer esto, se mataba o dañaba alguna parte de su cuerpo ${ }^{3}$.

\footnotetext{
${ }^{2}$ Arangio Ruiz, Vicenzo, Instituciones de Derecho Romano, Traducción castellana de la $10^{a}$ Edición italiana de Caramés Ferro, José, reimpresión de la 1ª Edición, Depalma, Buenos Aires, 1986, p. 418. En este sentido, también, SHIPANI, Sandro, Responsabilità "Ex lege Aquilia". Criteri di imputazione e problema della "culpa", Giappichelli, Turín, 1969, pp. 47-49, y BЕттı, Emilio, Istituzioni di Diritto Romano, vol. II, Cedam, Padova, 1962, pp. 512-513. Trata especialmente el principio del damnum corpore datum, Zııото, Paola, L'imputazione del danno aquiliano. Tra iniuria e damnum corpore datum, Cedam, Padova, 2000, pp. 6 y ss. Al respecto, la autora señala: "Nella prospettiva dell'estensione della tutela aquiliana, ciò che interessa è che Gaio dica che l'actio legis Aquiliae veniva concessa solo contro chi avesse provocado un danno corpore suo". El texto clave en esta materia es el pasaje gayano 3,219, según el cual: "Ceterum placuit ita demum ex ista lege actionem esse, si quis corpore suo damnum dederit, ideoque alio modo damno dato utiles actiones dantur, uelut si quis alienum hominem aut pecudem incluserit et fame necauerit, aut iumentum tam uehementer egerit, ut rumperetur; item si quis alieno seruo persuaserit, ut in arborem ascenderet uel in puteum descenderet, et is, si ascendendo aut descendendo ceciderit, aut mortuus fuerit aut aliqua parte corporis laesus sit. Sed si quis alienum seruum de ponte aut ripa in flume proiecerit et is suffocatus fuerit, hic quoque corpore suo damnum dedisse eo quod proiecerit, non difficiliter intellegi potest" " "Se ha admitido que en virtud de esta ley la acción se puede ejercitar sólo si alguien causa el daño directamente con su cuerpo, y por esto, para un daño causado de otro modo, se conceden acciones útiles, como, por ejemplo, si alguien encierra y deja morir de hambre y un esclavo o una cabeza de ganado que son de otro, o si persuade a un esclavo ajeno para que suba a un árbol o baje a un pozo, y éste, subiendo o bajando, se cae y se mata o se lesiona alguna parte del cuerpo. Por el contrario, se puede entender fácilmente que si alguien arroja a esclavo ajeno desde un puente o desde la orilla al río, y éste perece ahogado, aquí también se ha causado el daño con el propio cuerpo a aquel a quien se empujó"). El texto, tanto en latín como en castellano, ha sido tomado de Hernández Tejeiro, Francisco (Coord.), Abellan Velasco, Manuel; Arias Bonet, Juan Antonio; Iglesias Redondo, Juan; Roset Esteve, Jaime, Instituciones de Gayo. Edición bilingüe, Civitas, Madrid, 1985. Las referencias sucesivas estarán basadas en esta obra.
}

${ }^{3}$ Según Ulpiano, si uno convence a un esclavo ajeno para que suba a la rama de un árbol o baje a un pozo, éste lo hace y de dicha acción resulta muerto o lesionado, el que persuadió sólo es responsable del homicidio si lo ha hecho dolosamente. Pero, según Paulo, si ha existido culpa, debe responder según la lex Aquilia. Los textos corresponden al D. 11, 3, 3; 1, y D. 11, 3, 4. De acuerdo con el primero, de Ulpiano: "Dolo malo adiecto calliditem notat praetor eius qui persuadet: certerum si quis sine dolo deteriorem fecerit, non notatur, et si lusus gratia fecit, non tenetur. 1. Unde quaeritur, si quis servo alieno suaserit in tectum ascendere vel in puteum descendere et ille parens ascenderit vel descenderit et occiderit crusque vel quid aliud fregerit vel perierit, an teneatur: et si quidem sine dolo malo fecerit, non tenetur, si dolo malo, tenebitur" ("Mediante la expresión 'con dolo malo' que añade el pretor castiga éste la malicia del que persuade; pero no castiga si alguno empeora al esclavo sin dolo, y si lo hizo por broma no incurre en responsabilidad. 1. Por lo cual se pregunta: si alguno hubiese persuadido al esclavo ajeno a que suba a un tejado o baje a un pozo, y él, siguiendo el consejo, lo hubiese hecho, y al caerse se hubiera roto una pierna u otro miembro cualquiera o se matase, ¿incurre aquél en responsabilidad? Si verdaderamente lo hubiese hecho sin dolo malo, no, pero si fue con dolo malo, sí incurrirá en responsabilidad"). El segundo pasaje, atribuido a Paulo, señala: "Sed commodius est utili lege Aquilia eum teneri" ("Pero es más ventajoso que responda por una acción de la ley Aquilia útil, 
Además, desde que la ley tenía como objeto la protección del propietario, a éste competía el ejercicio de la acción, en principio ${ }^{4}$. Es por estas razones que la lex Aquilia se considera un típico ejemplo del formalismo que había caracterizado la jurisprudencia posterior a las XII Tablas.

Sin embargo, debemos hacer presente que hay voces que niegan, desde una diversidad de aproximaciones, la existencia del principio corpore corpori, como originario de la ley. Tenemos noticia al menos de 3 distintas posiciones. En primer lugar, Daube, quien desarrolla toda una teoría sobre la sanción contenida en el capítulo tercero de la lex Aquilia, que importa una comprensión del carácter originario de la ley como resarcitorio, entiende que una de las consecuencias de su tesis es la negación del principio corpore corpori. En efecto, según el autor, tanto Gayo como Justiniano, después del primero, declararon que la lex era disponible si quis corpore suo damnum dederit, que es bien distinto a sostener que en la ley se exigiera un damnum dare corpori. De esta manera: "...damnum corpori datum and, of course, damnum corpore corpori datum cannot be reconciled with the Roman usage". La expresión habría sido resultado de una introducción de los juristas medievales, desde que el daño no era utilizado para la destrucción o deterioro de las cosas, sino que para las pérdidas sufridas para el propietario ${ }^{5}$.

(en razón del daño culposo'). Para el texto en latín hemos seguido la obra de Mommsen, Theodorus; Krueger, Paulus, Corpus Iuris Civilis. Volumen Primum. Instituciones. Digesta, Weidmann, Hildesheim, 1988. Los pasajes en latín del Digesto que en adelante se citen, corresponden a esta obra. Para las versiones en castellano, hemos utilizado la traducción de D'Ors, Álvaro; Hernández Tejeiro, F.; FuentesecA, P.; García Garrido, M.; Burillo, J, El Digesto de Justiniano, Aranzadi, Pamplona, 1988.

Según Valı̃̃o, Emilio, Acciones útiles, Ediciones Universidad de Navarra, Pamplona, 1974, p. 340: "Todo el pasaje es un glosema postclásico, torpemente incluido por los compiladores en esta sede, pues en él se hace decir a Paulo todo lo contrario de lo que ha dicho Ulpiano en el fragmento anterior". En cambio, en opinión de Albanese, Bernardo, "Studi sulla legge Aquilia", AUPA 21, 1950, p. 48, se trata de un texto sustancialmente genuino, que reproduce el pensamiento clásico consagrado en Gayo 3, 219. En efecto, en su opinión, en este tipo de casos, en los que no existía conducta inmediata, es decir, daño non corpore, los clásicos habrían otorgado una actio utilis. Luego, el pasaje se correspondía con el texto de Gayo. Hay otros pasajes que el autor analiza en esta línea, como el del D. 47, 2, 50, 4, en el que Labeón otorgaba una acción útil en el caso que se espantara a un ganado con un paño rojo, el que tendremos oportunidad de estudiar.

${ }^{4}$ El pasaje del D. 9, 2, 11, 6 señala: "Legis autem Aquiliae actio ero competit, hoc est domino" ("La acción de la ley Aquilia compete al 'amo', esto es, al propietario').

${ }^{5}$ Daube, David, "On the use of the term damnum", en Studi in onore di Siro Solazzi, Casa Editriche Eugenio Jovene, Nápoles, 1948, pp. 98 y ss. Desde luego, no podemos detenernos en la discusión que los autores han planteado sobre el capítulo tercero de la lex. Una aproximación a este problema, se encuentra en nuestro trabajo Aedo Barrena, Cristián, "Los requisitos de la lex Aquilia, con especial referencia al daño. Lecturas desde las distintas teorías del capítulo tercero", lus et Praxis, Año 15, № 1, 2009, pp. 311-337, sin perjuicio del breve resumen que esbozaremos seguidamente.

En el capítulo tercero, se establecía que en caso de que el daño proviniera de una conducta que consistiera en quemar, quebrar o romper (urere, frangere, rumpere), se debía indemnizar con el valor que la cosa hubiese tenido dentro del período de los 30 días. Sin embargo, no es claro el período dentro 


\section{Continuación nota ${ }^{5}$}

del cual debía ser interpretada dicha sanción. El pasaje de Gayo 3, 218 utiliza la expresión fuerit y en D. 9, 2, 29, 8, se emplea la palabra fuit. Ambos verbos son indicativos de que la sanción tendría que haber sido empleada hacia el pasado, entendiéndola dentro de los 30 días anteriores al daño. Como desde este punto de vista habría una equiparación completa con el capítulo primero, también queda lógicamente explicada la indicación del mismo D. 9, 2, 29, 8, con arreglo al cual debía ser considerada en el capítulo tercero la expresión plurimi, es decir, que la indemnización, cualquiera fuera el perjuicio inferido, debía comprender el más alto valor de la cosa. El problema es que dichos pasajes se contradicen aparentemente con el texto del D. 9, 2, 27, 5, que utiliza la partícula erit, en cuyo caso la sanción debía ser entendida como dentro de los 30 días siguientes. Tales contradicciones han dado lugar a las más variadas teorías. Para una clasificación de las mismas, puede consultarse a MacCormack, Geoffrey, "On the third chapter of the lex Aquilia", The Irish Jurist 5, 1970, p. 165. En lo que respecta a la tesis de Daube, se encuentra en los siguientes trabajos: DAUBE, David, "On the third chapter of the lex Aquilia", LQR 52, 1936, pp. 253-255, y en DaUBE, David, Roman Private law. Linguistic, social and philosophical aspects, Edinburg University Press, Edinburgo, 1969, pp. 66 y ss. Le siguen, entre otros, CARDASCIA, G., "La portée primitive de la Loi Aquilia", en Watson, Alan (Edit.), Daube Noster. Essays in legal history for David Daube, Scotish Academic Press, Edimburgo, 1974, p. 62, y Watson, Alan, The law of obligations in the later Roman republic, Clarendon Press, Londres, 1965, p. 235, y en Watson, Alan, Roman Private Law around 200 BC, Edinburgh University Press, s.d., p. 153, sostiene que la teoría de Daube es la más satisfactoria en relación con el carácter originario del capítulo tercero. Tesis contrarias a este autor, con sus marcadas variantes, que no es del caso analizar aquí, pueden encontrarse en Jolowicz, H.F, "The original scope of the lex Aquilia and the question of damages", LQR 38, 1922, pp. 220 y ss., Van Warmelo, Paul, "A propos de la loi Aquilia", RIDA 27, 1980, pp. 345-348. Más recientemente, CANnATA, Carlo Augusto, "Il terzo capo dalla Lex Aquilia", BIDR 98-99, 1995-1996, pp. 120 y ss. También en CANNATA, Carlo Augusto, Sul problema della responsabilità nel Diritto Privato Romano, Libreria Editriche Torre Catania, Catania, 1996, pp. 109-110. Gran parte de estos autores considera que la otra tesis, de Daube, se funda en un error de transcripción del texto de Ulpiano en D. 9, 2, 27, 5, que contiene la expresión erit, pero el trabajo más profundo en esta línea sin duda alguna pertenece a ANKUM, Hans, "Quanta ea res erit in diebus XXX proximis dans le troisième chapitre de la lex Aquilia: un fantasme florentin", en Etienne Bravasa, Claude Emeri; Seurin, Jean Louis (Edits.), Mélanges en Hommage a Jacques Ellul. Religión, société et politique, PUF, París, 1983, pp. 179 y ss., explicando que la expresión se debe a un error del manuscrito florentino.

Apartándose de ambos puntos de vista, entre otros, Pugstey, David, "On the lex Aquilia and culpa", $T R$ 50, 1982, pp. 1-6, considera que los juristas clásicos utilizaron la sanción hacia el pasado, al igual que en el capítulo primero, pero rechaza su fundamentación en el pretendido carácter penal de la lex, considerando que dicho período tenía por función determinar el valor de acuerdo al costo de contratación de los esclavos o bienes animados heridos, lo que constituiría una gran mejora en relación con penas fijadas en las XII Tablas. KeLLy, John, "The meaning of the lex Aquilia", LQR 80, 1964, pp. 82 y ss, y Kelıy, John, "Further reflections on the lex Aquilia", en Studi in onore di Edoardo Volterra T. I, Giuffrè, Milán, 1971, pp. 235-239, propone una nueva reconstrucción del capítulo. En efecto, según su opinión, en el pasaje de Ulpiano en D. 9, 2, 27, 5 podía ser sustituida la expresión "damnum faxit" por "iniuria faxit", extrayendo la palabra iniuria desde su ubicación posterior a sus verbos (que al autor no le parece original) y luego separando la frase de la siguiente manera: "Si quis alteri iniuriam faxit// quod usserit fregerit ruperit // quati ea res erit // in diebus XXX proximis tantum aes dare damnas esto", para arribar a la consecuencia de que el período estuvo ligado a la manus iniectio y no directamente a la valoración de pérdidas.

Finalmente, ValditARA, Giuseppe, "Damnum iniuria datum", en PARICIO, Javier (Coord.), Derecho romano de obligaciones. Homenaje al profesor José Luis Murga Gener, Editorial Centro de Estudios Ramón Areces, Madrid, 1994, pp. 822 y ss., criticando ambas posiciones (más exactamente las de Daube y Jolowicz-Cannata), estima que la valoración era hacia el pasado (pues la partícula erit utilizada en D. $9,2,27,5$, se debería a un error de transcripción) y además, dicha valoración comprendía tanto a los bienes inanimados como animados, erigiéndose el capítulo tercero en una cláusula general de daños. 
Pugsley llega a una conclusión similar, pero desde una aproximación diferente, pues según el autor, los juristas clásicos adoptaron dos modelos distintos: uno de Gayo, que fijó la distinción en el principio corpore corpori, el que no se encontraba originalmente en los textos, de modo que la acción in factum se otorgó sólo en casos de causalidad mediata, método que, salvo por Juliano, no fue aceptado por otros. Así, el segundo modelo, perteneciente a Celso y a otros juristas clásicos, se fundó en el criterio de distinción entre occidere y causam mortis praestare. Ambos grupos coincidieron en algunas oportunidades, pero en otros casos se separaron. En cambio, los juristas republicanos, comenzando por Quinto Mucio, introdujeron la culpa o negligencia para desarrollar las acciones decretales, siendo la intencionalidad o conducta dolosa, la que permitía el otorgamiento de la acción directa ${ }^{6}$.

Desde otro punto de vista, también se pronuncia contra este principio Barton. El autor cuestiona que el principio corpore corpori haya sido una exigencia del texto legal de la ley, pues no existe nada en el texto de la norma que permita llegar a esta conclusión, considerando, en su opinión, que: "Moreover, although there is not a great deal of textual evidence for teh early history of the aquilian action, there are good reasons for believing thar this rectrictive interpretation of the lex is in fact no older than the beginning of the Pincipate, or the early classical period". Barton argumenta que parecería absurdo introducir una restricción tan seria a la aplicación de la lex Aquilia y, en cambio, conferir al demandante la acción pretoria en una amplia gama de casos, a menos que uno tuviese en cuenta la lis crecens, como sanción propia de la acción civil, que era evitada, de este modo, por la vía de la acción pretoria. En efecto, la posición del demandado, especialmente con la introducción de la culpa como requisito de la responsabilidad, habría sido muy desfavorecida, pues podría haber tenido motivos suficientes para negar la ocurrencia del hecho o de su responsabilidad en él y verse expuesto, por el contrario, al no confesar su responsabilidad, a la sanción por el duplo de la pena. Ello, por cuanto Barton entiende que, en efecto, determinar la concurrencia de la culpa en un caso concreto, pudo haber sido muy complejo y, en este sentido, el otorgamiento de una actio in factum pudo haber remedido un mecanismo legal que se presentaba anticuado, en el momento en el que la lex Aquilia se perfiló como una moderna acción de daños ${ }^{7}$.

Al margen de los cuestionamientos, lo cierto es que, desde la perspectiva tradicional, la labor de la jurisprudencia se tradujo en acciones pretorias que

Una mayoría de autos italianos sigue esta línea, con la excepción de CANnata. Véase, entre otros, Pugliese, Intituzioni, cit. nota n. 1, p. 605, y Bıondı, Biondo, Istituzioni di Diritto Romano, Giuffrè, $4^{\mathrm{a}}$ edición, Milán, 1965, pp. 528-531.

${ }^{6}$ Pugsley, "On the lex", cit. nota n. 5, pp. 3 y ss.

7 Barton, J.L, "The Lex Aquilia and Decretal Actions", en Watson, Alan (Edit.), Daube Noster. Essays in Legal History for David Daube, Scottish Academic Press, Edimburgo, 1974, pp. 21-24. 
tenían la función de extender el ámbito de la acción básica. Este grupo de casos, así denominado por Valiño, dice relación con la ampliación del ámbito de los daños tipificados y, más precisamente, con la ampliación de las acciones materiales de la ley ${ }^{8}$.

Las acciones materiales, tipificadas como damnum facere, que contemplaban los capítulos primero y tercero de la ley, se reducían a los verbos occidere, en el caso del primer capítulo, y, urere, frangere, rumpere, para el tercero ${ }^{9}$. Haremos breve repaso de la extensión de la acción tanto en el capítulo primero, como en el tercero.

\section{Evolución del verbo occidere: la distinción entre occidere y causam mortis praetare}

Originalmente, el verbo occidere consistía en la acción de matar realizada sobre el corpus del afectado. El vocablo occidere significaba tanto abatir, destruir, eliminar, hacer desaparecer, siendo el verbo matar el elemento constante. Esta acción exigía golpear hasta la muerte y, por lo mismo, suponía el contacto físico con la víctima ${ }^{10}$. Como explica Valditara, el verbo occidere tenía en la ley una significado más preciso y técnico que el lenguaje común, estando determinado a caedere/cades, en el sentido de golpear: "Occidere era anzi ricollegato alla medesima radice di caedere/caedes nel senso di percuotere/percossa, contenendo dunque in sè, come elemento qualificante, il riferimento ad un'azione materialmente svolgentesi sul corpus danneggiato"11.

\footnotetext{
${ }^{8}$ VAliÑO, Acciones útiles, cit. nota n. 3, pp. 334-342.

${ }^{9}$ Como señala BıGNARDı, Alessandra, "Frangere e rumpere nel lessico normativo en ella interpretatio prudentium", en Nozione, formazione e interpretazione del Diritto. Dall'età romana alle esperienze moderne. Ricerche dedicate al profesor Filippo Gallo, T. I, Jovene Editore, Nápoles, 1997, p. 29; 3637, estas acciones actuaron como limitaciones del damnum facere, siendo establecidas con el fin de individualizar los actos típicos a los cuales se refería el damnum, por cuanto el objeto de la ley se encontraba en la reparación de la lesión y no en la sanción de la conducta.

${ }^{10}$ Sobre esta conducta, tipificante del damnum facere, véase CASTRESAnA, Amelia, Nuevas lecturas de la responsabilidad aquiliana, Ediciones Universidad de Salamanca, Salamanca, 2001, pp. 28-32, у Zıııто, L'imputazione, cit. nota n. 2, p. 142, quien señala que, como se desprende de los textos contenidos en D. 9, 2, 7, 3. D. 9, 2, 9, 3. D. 9, 2, 11, 15, la ausencia de una relación corporal inmediata entre la conducta y el evento impedía recurrir a la actio legis Aquiliae.

${ }^{11}$ Valditara, "Damnum iniuria", cit. nota n. 6, p. 841. En el mismo sentido, entre otros, ZimmermanN, Reinhard, The Law of Obligations Roman Foundations of the Civilian tradition, Clarendon Paperbacks, OXford, 1996, p. 978. Bravo Bosch, María José, "Algunas consideraciones en torno a la Lex Aquilia", en Murillo VILlar, Alfonso (Coord.), Estudios de Derecho Romano en memoria de Benito María Reimundo Yanes, T. I, Ediciones Universidad de Burgos, Burgos, 2000, p. 32, indica que en la ley la expresión occidere se refería a la muerte producida adhibita vi y quasi manu, de manera que la expresión estaba vinculada con la raíz verbal caedere/caedes, en el sentido de golpear/golpe. También CoRBINO, Alessandro, Il danno qualificato e la lex Aquilia, Cedam, Milán, 2005, pp. 71-74, sostiene que en el lenguaje común, por el contrario, la expresión tenía un valor comprensivo de todo hecho causativo de muerte,
} 
Lo cierto es que la ampliación de la acción material de occidere, plasmada en el pasaje de Gayo, 3, 219, se debió a una evolución paulatina. Dicha evolución es explicada por Castresana ${ }^{12}$, quien indica que varias expresiones semánticas de la palabra permitieron a la jurisprudencia atenuar la exigencia de contacto directo sobre la víctima, lo que condujo, con Labeón, con un antecedente en Ofilio, a eliminar en primer lugar la necesidad de violencia en la acción de matar ${ }^{13}$. Posteriormente, con Celso va a verse perfilada la evolución jurisprudencial en torno al occidere, cuando la acción material de matar es

agregando que la interpretación restrictiva se debía al carácter penal de la acción de la ley. Para arribar a esta conclusión, interpreta la expresión rumpere como "dañar una parte del cuerpo", cuya raíz etimológica no está clara, pues puede provenir de la raíz rupo o rap, ligada a la raíz lup, atribuyendo en tal modo el significado de dañar, destruir; aun cuando hay ciertas derivaciones de la raíz latina, como los términos indios ropaiato (corte, rotura) y rùpyati, así como el antiguo islandes riufa (romper, arrancar) que hablan a favor de una tesis limitada de rumpere, comprendiendo sólo la extirpación de una parte del cuerpo. Sobre esta cuestión, véase también, BIGNARDI, "Frangere e rumpere", cit. nota n. 9, p. 17.

${ }^{12}$ Castresana, Nuevas lecturas, cit. nota n. 10, pp. 30-32.

${ }^{13}$ La responsa de Ofilio, aparece en D.9, 2, 9, 3, según el cual: "Si servum meum equitantem concitato equo effeceris in flumen praecipitari atque ideo homo perierit, in factum ese dandam actionem Ofilius scribit: quemadmodum si servus meus ab alio esset occisus" ("Si habiendo asustado al caballo hubiese hecho que fuera arrojado al río mi esclavo jinete y, a consecuencia de ello, el esclavo hubiera perecido, escribe Ofilio que ha de darse una acción por el hecho, lo mismo que si mi esclavo, conducido a una emboscada por una persona, hubiese sido muerto por otra"). Un análisis de este caso se encuentra en SCHIPANI, Responsabilità, cit. nota n. 2, pp. 326 y ss. Como indica MaCCormack, Geoffrey, "Juristic interpretation of the lex Aquilia", en Studi in onore di Cesare Sanfilippo, T. I, Giuffrè, Milán, 1982, p. 259, desde el punto de vista del método analógico, es difícil encontrar una razón que justifique un tratamiento común para los dos casos que aparecen en el pasaje -como el del caballo que se asusta y la conducción del esclavo a la emboscada. El aspecto común, según el autor, puede buscarse en que en ambos casos el resultado se produce por un agente independiente; en el primero, un caballo que se asusta, mientras que en el segundo, otro que mata, aunque debe reconocerse que la conexión parece bastante débil.

En lo que respecta a Labeón, se trata del caso contenido en D. 9, 2, 9: "Item si obstetrix medicamentum dederit et inde mulier perierit, Labeo distinguit, ut, si quidem suis manibus supposuit, videatur occidesse: sin vero dedit, ut sibi mulier offerret, in factum actionem dandam, quae setentia vera est: magis enim causam mortis praestitit queam occidit" ( $A$ su vez, si una comadrona hubiese dado una medicina y a consecuencia de ella hubiera perecido la mujer, Labeón distingue de modo que si la administró con sus manos se considera que mató, pero si la dio a la mujer para que ésta se la tomara debe darse una acción por el hecho. Y esta opinión es correcta, ya que, más que matar, proporcionó una causa de muerte"). Un amplio comentario del caso en Zııото, L'imputazione, cit. nota n. 2, pp. 143-149: "Per stabilire quale azione si debba concedere contro l'ostetrica Labeone distingue a seconda che l'ostetrica abbia inserito con le proprie mani il medicamentum nel corpo della paziente (supposuit suis manibus), ovvero glielo abbia solo offerto affinché lo prendesse da sé. Nel primo caso, infatti, Labeone ravvisa un comportamento che concreta un occidere e conseguentemente ritiene che contro l'ostetrica sia possibile concederé un'actio legis Aquiliae; nel secondo caso invece ritiene che contro l'ostretica si debba concederé un'actio in factum". En tanto, SCHIPANI, Responsabilità, cit. nota n. 2, pp. 322-323, analiza las implicancias de la causalidad. Un análisis de este caso y en general de las actuaciones médicas en Derecho romano puede encontrarse en Núñez PAZ, María Isabel, La responsabilidad de los médicos en Derecho romano, Gráficas Apel, Gijón, 1996, p. 122. 


\title{
trasladada a la ubicación de una persona en situación de muerte ${ }^{14}$. El final de recorrido es el texto de Gayo, que hemos citado. \\ En el mismo sentido, MacCormack, quien indica que el desarrollo de la regla pudo haber sido, más o menos, de la siguiente manera: durante las últimas décadas del siglo I a. C., las acciones in factum se otorgaron en casos que no podían ser
}

\begin{abstract}
${ }^{14} \mathrm{El}$ texto de Celso se encuentra en D. 9, 2, 7, 6: "Celsus autem multum interesse dicit, occiderit an mortis causam praestiterit, ut qui mortis causam praestitit, non Aquilia, sed in factum actione teneatur, unde adfert eum qui venenum pro medicamento dedit et ait causam mortis praestitisse, quemadmodum eum qui furenti gladium porrexit: nam nec hunc lege Aquilia teneri, sed in factum" "Dice Celso que hay diferencia si lo ha matado o si ha dado ocasión a la muerte, porque el que ha dado ocasión a la muerte no está sujeto a la ley Aquilia sino a la acción por el hecho. Y de ahí que mencione al que dio un veneno en vez de una medicina, y dice que dio pie a una causa de muerte lo mismo que el que proporciona una espada a un loco, ya que tampoco éste queda sujeto a la ley Aquilia sino a la acción por el hecho"). Es propuesto por VAlDITARA, "Damnum iniuria", cit. nota n. 5, p. 845, como una diferencia entre las acciones de la ley y las in factum: "Una espressa concettualizzazione della differenza tra l'ipotesi oggetto dellàzione aquiliana e quella oggetto di actiones in factum era contenuta nellòpera celsina: Celsus autem multum interesse dicit, occiderit an mortis causam praestiterit, ut qui mortis causam praestitit, non Aquilia, sed in factum actionem teneatur. È evidente che il concetto di mortis causam praestare era ritagliato all'interno del campo residuo, lasciato per le ipotesi in cui non ricorreva occidere".
\end{abstract}

De otra parte, según SCHIPANI, Responsabilità cit., nota n. 2, pp. 323-324, en Celso se produce una distinción entre occidere y causam mortis praestare: "considerando in primo luogo un caso in termini molto generali (venenum dare) che bien risolto affiancandolo ad uno di probabile origine nelle scuole retoriche (furioso gladium porrigere); viene contrapposto ad esso, quasi per porre súbito un limite all'applicazione di questa distinzione, il caso di colui che de ponte aliquem praeceipitavit, per il quale è conessa l'azione diretta análogamente all'ipotesi in cui taluno abbia colpito saxo puerum". En el mismo sentido, Zııюто, L'imputazione, cit. nota n. 2, pp. 150-151, quien señala: "Celso, dunque, dice che è molto importante distinguere tra colui che ha ucciso (occiderit) e colui che ha dato causa alla morte (mortis causam praestitit), perché colui che ha dato causa alla morte non è tenuto in base alla lex Aquilia ma con una actio in factum".

Según MACCORMACK, "Juristic interpretation", cit. nota n. 13, p. 259, no se puede estar seguro si entre los ejemplos comparados se aduce un argumento por analogía o simplemente ambos ejemplos permiten ilustrar la regla sentada más arriba por Celso. Pero fuera de esta cuestión, el punto de similitud entre los dos casos, en que se entrega una espada a un loco para que se dé muerte y el veneno que se da para que otro lo tome, se encuentra en que en ambos se entrega un instrumento para que la misma víctima se quite la vida: "One probably has to suppose that the intention to kill is present in both cases but the critical point of similarity appears to be that the victim killed himself with an instrument given to him by someone else".

De otra parte y desde una perspectiva temporal, como explica WATSON, Alan, "Narrow, rigid and literal interpretation in the later Roman Republic", TR 37, 1969, pp. 353-355, la distinción de Celso es un buen ejemplo de cómo la interpretación literal de los verbos y la diferenciación entre y dar ocasión de muerte, fue mucho más importante en la época del Imperio que en la época republicana, aun cuando dicha diferenciación reconoce una regla más antigua, como es el caso de la comadrona, decidido por Labeón, en D. 9, 2, 9 pr. Según el autor, un precedente más antiguo a la distinción de Celso puede encontrarse en la decisión de Labeón, de D. 9, 2, 3, 9. También vincula esta decisión de Celso con anteriores, MACCORMACK, "Juristic interpretation", cit. nota n. 13, pp. 261-262. Según el autor, en D. 9, $2,9,1$, Ulpiano utiliza la analogía con el caso de la comadrona para llegar a una conclusión similar, en el sentido de administrar directamente una medicina a otro, mediante jeringa o por vía oral. Las similitudes entre ambos casos no dejan lugar a dudas en la utilización de ella, pero lo que hace Ulpiano es generalizar la regla sentada por Labeón. 
tratados como occidere (en estricto rigor, cuando para los juristas no era posible aplicar el método analógico y entonces éste resultaba quebrantado). Después, comenzaron a buscar un principio subyacente que fijara el criterio para otorgar una actio legis o una actio in factum. Hasta antes de la concreción de la fórmula, sin embargo, parece haber habido entre los juristas un amplio margen de apreciación para determinar cuándo otorgar una actio in factum y cuando no ${ }^{15}$.

Así, según MacCormack, Celso es el primer jurista que extrajo de los casos de daño causado non corpore una regla determinante respecto de cuando procedía la acción de la lex Aquilia y cuando una actio in factum, pero más adelante reconoce que el criterio de Celso era difícil de aplicar en la práctica: "Celsus' distinction between occidere and mortis causam praestare is verbally neat but may not have been easy to operate in practice ${ }^{\prime 16}$. En efecto, debemos tener en cuenta que según un grupo de autores, era la acción útil la que se otorgó para resolver casos en que había un daño en la materialidad física de la cosa dañada (damnum corpori), pero no mediante un acto físico directo de lesión, es decir, non corpore, de modo que sirvieron para resolver, precisamente, problemas de causalidad mediata. La actio in factum se confería, por el contrario, cuando no se afectaba la materialidad física de la cosa o ésta no resultaba destruida, aun cuando reconocen que en el Digesto la denominación vino a ser cambiada por la de actio in factum ${ }^{17}$.

Con todo, la mayoría de los casos en los que no hubo causalidad directa se otorgaba una acción in factum. Un magnífico ejemplo es el caso de la comadrona en D. 9, 2, 9. Según Labeón, si ésta proporcionaba directamente el medicamento, había acción directa; si hacía que lo tomara, en cambio, la víctima, procedía el otorgamiento de una actio in factum. Lo reiteraba Ulpiano, en D. 9, $2,9,1$, utilizando la analogía. Hay otros, no obstante, en que la denominación es de actio utilis (aun cuando para el capítulo tercero y no el primero), como el caso de los esclavos horneros, en D. 9, 2, 27, 9, en que se concedió una acción útil contra el hornero que se quedaba dormido junto al horno y permitía que

\footnotetext{
${ }^{15}$ MACCORMACK, "Juristic interpretation", cit. nota n. 13, pp. 266-269.

${ }^{16}$ MacCormack, Geoffrey, "Aquilian Studies", SDHI 41, 1975, pp. 21-24.

17 Por todos, Albanese, "Studi", cit. nota n. 3, pp. 5- 49. De hecho, el autor analiza varios casos en los que al no haber contacto directo con la víctima fue otorgada la acción útil. Sin perjuicio de algunos que tendremos la oportunidad de examinar, un pasaje interesante citado por el autor es el de Ulpiano, en D. 19, 2, 13 pr: "Item quaeritur, si cisiarius, id est carucarius, dum ceteros transire contendit, cisium evertit, et servum quassavit vel occidit; puto, ex locato esse in eum actionem, temperare enim debuit; sed et utilis Aquilia ei dabitur" "Asimismo se pregunta, si el calessero, esto es, el cochero, vuelca, por disputar pasar delante de otros, la calesa, y estropeó o mató a un esclavo; opino que hay contra él la acción de locación, porque debió moderarse; pero también se le dará a éste la acción útil de la ley Aquilia"). Para este problema, puede consultarse nuestro trabajo Aedo BarRena, Cristián, "La actio legis aquiliae: concepto, características y desarrollo decretal posterior. Lecturas desde el capítulo tercero", Revista de Derecho Universidad Católica del Norte 16, 1, 2009, pp. 40-52.
} 
se propagara el fuego, pero en el pasaje se deja constancia expresa de que no pudo otorgarse la acción directa, porque éste nada había hecho. Por el contrario, hay algunos supuestos en los que se concedía la acción directa, aun cuando la causalidad era mediata, como en la opinión de Próculo, en el caso en que se irrita a un perro para que muerda a otro, en el pasaje del D. 9, 2, 11, 5.

Como hemos dicho, las distintas interpretaciones de situaciones similares son bastante notorias, de manera que en algunas se otorgó la actio legis Aquiliae, a pesar que no había una conducta directa e inmediata del ofensor. Baste citar y analizar, brevemente. Algunos ejemplos, como el pasaje de Servio, en D. 9, 1, 1,4 , vinculado a otras dos decisiones muy similares. Nos referimos al pasaje de Bruto, en D. 9, 2, 27, y otro muy similar de Alfeno en D. 19, 2, 30, 2.

En primer pasaje, del D. 9, 1, 1, 4, se atribuye a Servio Sulpicio Rufo ${ }^{18}$. De acuerdo con el pasaje, si el daño se ha debido a la ferocidad del animal, procede la actio de pauperie y, la acción directa de la lex Aquilia, cuando ha intervenido la culpa del mulero ${ }^{19}$. El caso propuesto por Servio en D. 9, 1, 1, 4 está vinculado a dos decisiones muy similares. En primer lugar, con un pasaje de Bruto, en D. 9, 2, 27, 23, en el que se lee: "Et si mulum plus iusto oneraverit et aliquid membri ruperit, Aquiliae locum fuore" ("y que tendrá lugar la ley Aquilia si alguien hubiese cargado a un mulo más de lo justo y le hubiese roto algún miembro"). En este caso, no hay duda que el resultado puede traducirse en un rumpere, pero resulta dudoso que la conducta pudiera ser calificada como intervención directa sobre la cosa. Aún así, Bruto entendió que procedía la actio legis. En un caso bastante similar (D. 19, 2, 30, 2), Alfeno también consideraba procedente la acción de la ley, pero agregaba un elemento que nos parece importante: dicha acción se otorgaba contra quien había cargado directamente las mulas y no otro $^{20}$. Debemos reconocer, en todo caso, que aun cuando son casos similares,

\footnotetext{
${ }^{18}$ El pasaje en cuestión reza: "Itaque, ut Servus scribit, tunc haec actio locum habet, cum commota feritate nocuit quadrupes, puta si equus calcitrosus calce percusserit, aut bos cornu petere solitus petierit, aut mulae propter nimiam ferociam: quod si propter loci iniquitatem aut propter nimiam ferociam: quod si propter loci iniquitatem aut propter culpam mulionis, aut si plus iusto onerata quadrupes in aliquem onus everterit, haec actio cessabit damnique iniuriae agetur" ("Así pues, como escribe Servio, tiene lugar esta acción cuando, movido por su ferocidad, un cuadrúpedo hizo algún daño; por ejemplo, si un caballo coceador hubiera golpeado con una pata, o un buey acostumbrado a embestir hubiera embestido, o unas mulas <hicieran algún daño> por su excesiva fiereza. Pero si por lo accidentado del terreno o por culpa del mulero, o por ir más cargado de la cuenta el cuadrúpedo hubiera lanzado la carga sobre alguno, cesará esta acción y se demandará sobre el daño injusto").

19 Sobre la actio de pauperie y, especialmente, el significado originario del término y su posterior desarrollo, véase a WATSON, Alan, "The original meanings of pauperies", RIDA 17, 1970, pp. 357-367. Indica que en su significado originario pauperie indicaba simplemente "falta de productividad" y que en el transcurso del tiempo pasó a identificar las pérdidas causadas sin culpa del agente, limitándolo a los daños provocados por animales.

${ }^{20}$ El pasaje en cuestión señala: "Qui mulas ad certum pondus oneris locaret, cum maiore onere conductor eas rupisset, consulebat de actione, respondit vel lege Aquilia vel ex locato recte eum agere, sed lege Aquilia
} 
por cuanto se trata de conductas no destinadas directamente a causar daños a otros, o al animal, éste se produce como consecuencia de una conducta inicial culposa, pero las semejanzas acaban allí. En los dos últimos casos, se trataba de un daño inferido al animal y no al tercero, por lo que técnicamente no pueden ser calificados de problemas de causalidad mediata, pero en éstos, al igual que la primera situación, lo interesante es que no hubo una acción dirigida a provocar un perjuicio, como un golpe o una herida, sino que son casos en los que dicha conducta se equipara a rumpere. Pero lo importante, en definitiva, es que la sanción que otorgaron los juristas fue la de la lex Aquilia, a pesar de tratarse de problemas de causalidad mediata, como ocurre igualmente con la opinión de Pegaso, informada por Ulpiano, en D. 9, 2, 7, $2^{21}$.

Volviendo al pasaje en análisis, como explica Del Castillo, merece destacarse el hecho de que el jurista decidiera sobre la procedencia de la acción de daño injusto y la consecuente inaplicación de la actio de pauperie, partiendo de las siguientes circunstancias: a) por lo accidentado del lugar; b) por culpa del mulero; c) si por ir más cargado de lo que podía soportar la mula hubiere lanzado la carga encima de alguien ${ }^{22}$. En estos supuestos, como indica Martínez Sarrión, el protagonismo ha dejado al animal para pasar al hombre, pues en estas situaciones lo relevante era la imprudencia o imprevisión ${ }^{23}$.

De otra parte, el pasaje presenta dos órdenes de problemas. El principal dice relación con la expresión damnique iniuriae agetur. Así, por ejemplo, Schipani, sostiene que la expresión que se lee en el párrafo cuarto es más amplia que la

tantum cum eo agi posse, qui tum mulas agitasset, ex locato, etiam si alius eas rupisset, cum conductore recte agi" ("El que había arrendado unas mulas para una carga de cierto peso, habiéndolas derrengado el arrendatario a causa de un peso mayor, consultaba respecto a la acción competente. Respondió que era correcto demandar por la acción de la ley Aquilia o por la de locación; pero por la acción de la ley Aquilia sólo podría demandar contra aquél que en aquella ocasión hubiese llevado las mulas; por la acción de locación, aunque otro las hubiese derrengado, se demanda rectamente al arrendatario").

21 "Sed si quis plus iusto oneratus deiecerit onus et servum occiderit, Aquilia locum habet: fuit enim in ipsius arbitrio ita se non onerare. Nam et si lapsus aliquis servum alienum onere presserit, Pegasus ait lege Aquilia eum teneri ita demum, si vel plus iusto se oneraverit vel neglegentius per lubricum transierit". ("Pero si alguien, cargado más de la cuenta tomase la carga y hubiera matado a un esclavo, se aplica la ley Aquilia, ya que dependió de su discreción el no cargarse así. Pues también si alguien resbalando hubiera aplastado con la carga a un esclavo ajeno, dice Pegaso que es responsable por la ley Aquilia si se hubiese pasado negligentemente por un terreno resbaladizo"). Como afirma DEL Castillo Santana, María Soledad, Estudio sobre la casuística de las lesiones en jurisprudencia romana, Dykinson, Madrid, 1994, pp. 48-49, ambos párrafos constituyen una generalización de la decisión de Servio, en D. 9, 1, 1, 4.

22 Del Castillo, Estudio, cit. nota n. 21, p. 141.

${ }_{23}$ Martínez Sarrión, Ángel, Las raíces romanas de la responsabilidad por culpa, Bosch, Barcelona, 1993, pp. 448-449. El problema es que, como afirma MACCORMACK, Goeffrey, "Aquilian culpa", en Watson, Alan (Edit.), Daube Noster. Essays in legal history for David Daube, Scotish Academic Press, Edimburgo, 1974, p. 212, ni Servio ni Ulpiano señalaron qué debía entenderse en este grupo de situaciones por culpa. 
expresión actio legis Aquiliae, ello porque en su concepto, el párrafo séptimo (e implícitamente los párrafos quinto a sexto, de Ulpiano) permite concluir que se hace referencia a una actio in factum ${ }^{24}$. No comparte esta opinión Zilioto, quien entiende que en los párrafos quinto y sexto, Ulpiano no habría omitido la referencia a la acción que se otorgaba, pues estaba claro que seguía la opinión de Servio. En cambio, la referencia en el párrafo séptimo a la actio in factum tiene como explicación que Ulpiano arrancaba de un supuesto distinto. Mientras que en los párrafos cuarto a sexto el antecedente causal determinante era la actuación humana culposa, en el párrafo séptimo la atención se traspasa del elemento subjetivo a uno objetivo, y es por eso por lo que se prefirió recurrir a la actio in factum ${ }^{25}$. En segundo término, también se discute cuánto del pasaje puede ser atribuido al pensamiento del republicano Servio $^{26}$.

¿Cómo explicar las claras contradicciones que existen entre estos dos tipos de casos, en los que en algunos se optaba por la actio legis Aquiliae, mientras que en otros se otorgaba derechamente una actio in factum? Volvemos a hacer presente que en este problema, como en otros, no puede dejarse de lado ninguna consideración de carácter temporal. Si se analizan las decisiones contradictorias que venimos comentando, tal parece que la tesis de MacCormack lleva razón, en cuanto a que antes de quedar fijada la fórmula de Celso, los juristas tenían un amplio margen para determinar cuándo se otorgaba, y cuando no, una actio in factum. $Y$ así, todas las decisiones que hemos citado, que parecen oponerse al criterio de Celso o que son al menos oscilantes, pertenecen a juristas anteriores al mismo, bien republicanos, bien clásicos anteriores a Celso. Por ejemplo, la decisión de Ofilio en D. 9, 2, 9, 3, jurista republicano, emplea un criterio que, aunque anterior, será similar al de Celso, porque como hemos visto, los autores están de acuerdo en que su opinión puede citarse como precedente de

\footnotetext{
${ }^{24}$ SCHIPANI, Responsabilità, cit. nota n. 2, p. 163. Es significativo que Watson, "D. 7.1.13.2 (Ulpian 18 ad Sab.). the lex Aquilia and decretal action", Iura 17, 1966, pp. 175 y ss., concluyera igualmente que en el pensamiento de los juristas romanos se utilizaba la expresión actio legis Aquiliae o alguna otra análoga para referirse a las acciones decretales que eran otorgadas en el círculo cercano de la ley.

${ }^{25}$ Zııото, L'imputazione, cit. nota n. 2, pp. 109-114.

${ }^{26} \mathrm{Al}$ respecto, véanse las discusiones filológicas entre SCHIPANI, Responsabilità, cit. nota n. 2, pp. 163 164, y WATSON, The law, cit. nota n. 5, p. 281. El primero piensa que esencialmente el pasaje puede atribuirse al pensamiento de Servio, mientras que Watson entiende que desde "quod si" hasta el final del texto, es obra de los compiladores, lo que probaría el indicativo cessabit. Para Watson, hay varias inconsistencias derivadas de la utilización de los tiempos verbales, que le hacen pensar que se trata de un texto recortado por los compiladores y que es Ulpiano el que estaba informando en parte una opinión de Servio. Por el contrario, Schipani supone que el desarrollo de todos los párrafos, del cuarto al séptimo, permite demostrar que es un pasaje que puede atribuirse a Servio, pues en el párrafo séptimo hay una repetición general inexplicable si Ulpiano no estuviera dando cuenta del parecer de otro. Para Martínez SARRIÓn, Las raíces romanas, cit. nota n. 23, pp. 449-450, es imposible dilucidar la autoría del texto, al acoger Ulpiano las ideas de Servio.
} 
la regla. Lo mismo ocurre con Labeón, jurista clásico anterior, que parece ser el siguiente paso de la cadena.

Pero otras opiniones de juristas republicanos o clásicos anteriores a Celso utilizan un criterio distinto. Una de las decisiones más antiguas pertenece al jurista republicano Bruto, que se ubica durante el siglo II a.C., quien en D. $9,2,27,23$, se decide por una acción directa y lo mismo ocurre con Mela, quien en el caso en el que se asusta al caballo y como consecuencia, se arrancaba el dedo del esclavo, otorgaba una acción directa. La decisión más próxima a Celso es la de Sabino, jurista clásico del siglo I d.C, quien en D. $9,1,1,4$ se decidía por una actio legis. Para terminar de delinear el cuadro, coincidentemente Juliano, jurista clásico posterior a Celso, a quien debemos suponer conocedor de la regla, en el pasaje de Próculo, en D. 9, 2, 11, 5, se decide por la actio in factum para un problema de causalidad mediata y sólo concede la acción directa en contra de quien sostenía con su mano al perro que daña a otro.

Finalmente, digamos que frente a tales problemas, algunos autores han argumentado que la culpa fue utilizada como criterio que servía para la resolución de estas cuestiones, es decir, que los juristas romanos se valieron de materiales culpabilísticos cuando la causalidad no se presentaba idónea (o derechamente no existía) para atribuir responsabilidad a un sujeto ${ }^{27}$.

\section{INTERPRETACIÓN DE LOS VERBOS "URERE, FRANGERE, RUMPERE" Del CAṔ́tUlo terCero de LA LEX AQUiLIA}

En lo que respecta a las acciones urere, frangere y rumpere, utilizadas en el capítulo tercero de la lex Aquilia, Castresana nos dice: "Cualquiera de estas tres acciones verbales implicaba otras tantas conductas materiales de "damnum facere", por lo que se excluía de su ámbito originario de aplicación la pérdida de cosas intervenida non corpore o non facere ${ }^{\prime \prime 28}$. Sin embargo, como veremos, al igual que la acción material de occidere, estos verbos experimentaron un proceso de interpretación amplificadora por parte de la jurisprudencia republicana.

\footnotetext{
${ }^{27}$ MacCormack, "Aquilian Studies", cit. nota n. 16, p. 13. Zıııто, L'imputazione, cit. nota n. 2, pp. 126 y 139, hace un análisis a propósito de la causalidad mediata, aunque con una óptica distinta, pues sostiene que en caso de concurrir diversos factores causales, algunos juristas, como Servio, Mela y Alfeno, utilizaron el elemento subjetivo como determinante para resolver el problema causal. En tales textos, sostiene que la jurisprudencia otorgó siempre la actio directa. No obstante, explicando la contradicción de Próculo señala que éste, en el caso del perro irritado, 11,5, habría seguido la tradición: "Tuttavia sembra che più elástica soluzione offerta da Proculo nel caso del cane aizzato si possa riallaciare alla tradizione di concedere l'azione civile in casi similari, quali ad esemplio quelli già menzionati del telum o dell'asino che sfugge (vedi Alfeno, D. 9, 2, 52, 2) o quello ricordato da Ulpiano in D. 9, 1, 1, 6".

${ }^{28}$ Castresana, Nuevas lecturas, cit. nota n. 10, p. 33.
} 
En lo que respecta al verbo urere, que significaba literalmente quemar, estaba referido al incendio de una casa o de plantaciones ${ }^{29}$. Como afirma Schipani: "L'analisi dell'urere si svolge, como quella dell'occidere, in modo complesso, con un intrecciarsi di problema che possono essere riferiti alla condotta intesa in senso lato, come contrapposta all'evento; questo d'altra parte non richiede una precisazione come invece richiederà per il rumpere; quella invece va ampiamente analizzata data la catteristica di porre in atto un fattore causale particularmente capace di autonomo sviluppo ${ }^{\prime 30}$. Por eso, Zilioto explica que en los comentarios de Ulpiano, se encuentra el caso paradigmático de quien incendia una cosa de otro. Todos los casos analizados tienen una circunstancia común, consistente en que el fuego no se aplicaba directamente a la cosa quemada, sino que provenía de otro lugar. Y por eso que en estos supuestos había un problema de causalidad ${ }^{31}$. Precisamente, esta ha sido la vía de aplicación del verbo por la jurisprudencia, como veremos al examinar el verbo rumpere.

En cuanto a frangere, como indica Valditara, hay pocos ejemplos, como el del artesano que destroza el cáliz que debía decorar, en D. 9, 2, 27, 2932. En todo caso, fue un verbo que quedó finalmente comprendido en la interpretación amplia de rumpere. Este verbo, ubicado al final de la lista, cumplía la función

${ }^{29}$ Se encuentra comentado en el texto de Ulpiano, en D. 9, 2, 27, 7-12. Como indica Zıııто, L'imputazione, cit. nota n. 2, p. 161, también se encuentra un comentario de Ulpiano, en la Collatio (XII, 7), con el título de Incendiariis.

${ }^{30}$ SCHIPANI, Responsabilità, cit. nota n. 2, p. 334.

${ }^{31}$ Zııото, L'imputazione, cit. nota n. 2, pp. 162-163, según quien: "Nascono così problema di responsabilità per chi ha acceso il fuoco, i quali però appaiono frammisti a problemi di causalità (e quindi a problemi di mezzi processuali utilizzabili). Questo casi consistono nell'ipotesi dell'incendio volontario di un'insula che si propaga alla casa vicina, nell'ipotesi del fuoco lecitamente acceso nel proprio fondo estesosi al fondo vicino, infine nell'ipotesi del fuoco diligentemente acceso da una persona addetta ad una fornace ma custodio negligentemente da un'altra con la conseguenza che la villa si incendia". Por ejemplo, señala Valditara, "Damnum iniuria", cit. nota n. 5, p. 850, que en supuestos como incendio propagado al campo del vecino, cuando el fuego se había prendido en propio campo, se concedía una actio in factum y no una actio ex lege Aquilia. En este caso, había una actividad lícita, en la que no podía explicarse un comportamiento positivo sobre el campo del vecino, que había resultado posteriormente destruido.

${ }^{32}$ ValditARA, "Damnum iniuria", cit. nota n. 5, p. 847. Según el texto: "Si calicem diatretum faciendum dedisti, si quidem imperitia fregit, damni iniuria tenebitur: si vero non imperitia fregit sed rimas habebat vitiosas, potest ese excusatus: et ideo plerumque artífices convenire solent, cum eiusmodi materiae dantur, non periculo suo se facere, qua res ex locato tollit actionem et Aquiliae" ("Si diste una copa para taladrar en ella un calado, quedará obligado por daño injusto el que la rompió por impericia. Pero si no la rompió por impericia sino porque tenía hendiduras defectuosas, puede ser excusado y de ahí que los artífices suelen convenir muchas veces, al serles dados tales materiales, que no lo hacen a su riesgo, y esto elude la acción de locación y la Aquilia"). 
de clausura del sistema, incorporando los supuestos específicos de los verbos urere y frangere f $^{33}$.

Es esta función de clausura y la interpretación amplia de rumpere lo que explica la evolución interpretativa por parte de la jurisprudencia. La ampliación a otros supuestos va a venir de la mano de la comprensión del verbo rumpere como corrumpere. En un comienzo, se entendía que había rumpere cuando existía una alteración sustancial del corpus que se agredía, de manera que sólo se configuraba una lesión o daño en el caso de pérdida patrimonial para el propietario. Tampoco se configuraba la acción si existía un perjuicio patrimonial derivado de la pérdida de disponibilidad de la cosa, pero cuando ésta no había mutado ${ }^{35}$. Es a partir del siglo I a.C. que la jurisprudencia va a ampliar el concepto analizado, para incorporar los deterioros. Según la reconstrucción

\footnotetext{
${ }^{33}$ ValditarA, "Damnum iniuria", cit. nota n. 5, p. 847. En efecto, como indica el autor citado: "Ebbne è significativo come qui rumpere riassuma tutte le ipotesi di danneggiamento diverse dalla occiso della bestia. Pare quindi certo chè già negli uitmi deceni III sec a.C. rumpere avesse un significato tendencialmente onnicomprensivo. Certamente ricomprendeva il frangere; resta peraltro legittimo qualche residuo dubio sul fatto che ricomprendesse anche l'urere: trattandosi de animali, una ustione che comportasse solo un ferimento doveva essere assai rara; ciò potrebbe spiegare il perché non si sia sentità l'esigenza di prevederla espressamente". Agrega: "In questo contesto è anche possibile che rumpere, collocato alla fine dell'elencazione delle condotte considerate, svolgesse una funzione di chiusura. Como si è osservato, la previa, specifica elencazione di urere e frangere doveva tra l'altro sottolineare come le ipotesi relative, sino ad allora partitamente disciplínate, dovessero considerarsi ormai superate dalla disciplina aquiliana".

${ }^{34}$ CORBINO, Il danno, cit. nota n. 10, p. 76, sostiene que al verbo rumpere se le otorgó en el lenguaje jurídico un significado elástico, que permitía comprender las expresiones verbales urere y frangere. Para BIGNARDI, "Frangere e rumpere", cit. nota n. 9, pp. 56-57, la peculiaridad de rumpere, en tanto que se trataba de un concepto amplio, que presentaba diversos significados, fue atribuida ya desde la época decenviral y fue lo que permitió a la jurisprudencia utilizar el verbo para la ampliación del ámbito de aplicación de la ley.

Con todo, se trata de una expresión de Celso, en D. 9, 2, 27, 16, con la que se concluyen dos párrafos previos, en los que señalaba casos en los que se había interpretado corrumpere. El pasaje que citamos señala: "Et non negat fractum est ustum contineri corrupti appellatione, sed non ese novum, ut lex specialiter quibusdam enumeratis generale subiciat verbum, quo specialia complectatur: quae sententia vera est" ("Y no niega que lo quebrado y quemado se incluye en la denominación de 'corrompidos', sino que no es nuevo que una ley, enumeradas específicamente ciertas cosas, añada un vocablo general que abarque las específicas. Esta opinión también es cierta"). Comenta MACCORMACK, "Aquilian Studies", cit. nota n. 16, pp. 6-8, que este párrafo parece una versión resumida de las ideas de Celso, pues no existe un recuento de los argumentos que le llevaron a interpretar corrumpere por rumpere. En una explicación bastante interesante adjudica un papel fundamental en el desarrollo de la noción de corrumpere y destaca que: "Is not imposible that Celsus was the first jurist to make extensive use of corrumpere and it seems likely that he was the first to hold that rumpere might in general be understood as corrumpere".

${ }^{35}$ CASTResana, Nuevas lecturas, cit. nota n. 10, pp. 33-34. Este es el pensamiento de CANnATA, "Il terzo capo", cit. nota n. 5, pp. 130-132, quien agrega que la ampliación del ámbito de la ley se produce porque va a ser insostenible mantener los verbos sólo para los supuestos de destrucción o eliminación de la cosa, de modo que la jurisprudencia comenzó a aplicarlos a los casos de simple deterioro para el propietario.
} 
de Cannata, el trabajo de la jurisprudencia puede ser fijado en el transcurso de unos 50 años desde la dictación de la ley ${ }^{36}$.

El punto de partida de este cambio interpretativo se ve reflejado en el texto de Ulpiano, en un pasaje atribuido a Bruto, en D, 9, 2, 27, 22: "Si mulier pugno vele equa ictu a te percussa eiecerit, Brutus ait Aquilia teneri quasi rupto" ("Si golpeada por ti una mujer con el puño, o una yegua, hubiere malparido, dice Bruto que quedas obligado por la ley Aquilia como por cosa corrompida") $)^{37}$. Y, según los autores, la evolución o tránsito de rumpere a corrumpere puede apreciarse en un caso similar, contenido en el D, 9, 2, 39, en una decisión atribuida a Quinto Mucio $^{38}$. El corolario de este pasaje es el siguiente, en D, 9, 2, 39, $1^{39}$.

${ }^{36}$ Cannata, "Il terzo capo", cit. nota n. 5, p. 132. Pringsheim, F., "The origin of the Lex Aquilia", Mélanges Henry Lévy-Bruhl, Institut du Droit Romain de l'Université de Paris, París, 1959, pp. 242-243, ha sostenido que el texto originario de la ley se refería sólo a los esclavos y al ganado, de modo que el trabajo interpretativo de la jurisprudencia tuvo por objeto, contrariamente a las ideas de Cannata, aplicar dichos verbos a los objetos inanimados. Señala: "The conclusion is justified that in the middle of the 2 nd century B.C there remained a residue of reminiscence that "rumpere" had originally been restricted to b). Later only this restriction disappeared completely, and the application to "res" prevailed". En sus planteamientos, "b)", corresponde a una segunda ley que habría pasado a formar parte de la definitiva lex Aquilia, referida sólo a las heridas de esclavos y animales.

Fuera de esta cuestión, MACCORMACK, "On the third", cit. nota n. 5, pp. 170-171 resume la evolución del verbo. Distingue tres diferentes procesos. En el primero, el verbo estaba referido a los daños menores, donde el esclavo recibe un golpe o un corte. Una segunda etapa la constituye lo que nosotros analizaremos como quasi rumpere. Propone el caso del D. 9, 2, 27, 18, en la situación de que alguien hubiere manchado o rasgado vestidos, es responsable como si hubiese roto. Se trata de casos en los que el daño físico no es suficiente para configurar el verbo. Finalmente, los juristas republicanos tardíos efectuaron la extensión de rumpere a corrumpere.

${ }^{37}$ Un análisis del texto puede encontrarse en BIGNARDI, "Frangere e rumpere", cit. nota n. 9, pp. 40-51 y en el mismo Cannata, "Il terzo capo", cit. nota n. 5, pp. 134-138. Como indica MacCormack, "Aquilian Studies", cit. nota n. 16, pp. 3-4, en el caso citado la responsabilidad depende de la interpretación de rumpere. Para arribar a dicha interpretación Bruto parece entender el feto como una prolongación del cuerpo de la madre.

${ }^{38}$ Según el pasaje: "Quintus Mucius scribit: equa, cum in alieno pasceretur, in cogendo quod praegnas erat eiecit: quaerebatur, dominus eius possetne cum eo qui coegisset lege Aquilia agere, quia equam in iciendo ruperat. Si percussisset aut consulto vehementius egisset, visum est agere posse" "Escribe Quinto Mucio: una yegua preñada que estaba pastando en campo ajeno, malparió al ser expulsada con violencia; se preguntaba si el dueño podía demandar por la ley Aquilia al que la hubiera expulsado, porque había corrompido a la yegua en su violencia. Si la hubiese golpeado o la hubiese tratado deliberadamente con excesiva violencia, pareció que podía demandar").

${ }^{39}$ Así lo afirman BignaRDI, "Frangere e rumpere", cit. nota n. 9, p. 51. CANNATA, "Il terzo capo", cit. nota n. 5, p. 138. En cuanto al pasaje: "Quamvis alienum pecus in agro suo quis deprehendit, sic illud expellere debet, quomodo si suum deprehendisset, quoniam si qui(d) $\langle s\rangle$ ex ea re damnum cepit, habet proprias actiones, itaque qui pecus alienum in agro suo deprehenderit, non iure id includit, nec agere illud aliter debet quam ut supra diximus quasi suum: sed vel abigere debet sine damno vel admonere dominum, ut suum recipiat". ("Dice Pomponio: aunque alguno encuentre una res ajena en su campo, la debe expulsar lo mismo que si hubiera encontrado una suya, porque si con ello recibió algún daño tiene las acciones adecuadas. Y así, quien hubiese encontrado en su campo una res ajena, ni la encierra 
En verdad, como expone MacCormack, hay cierta contradicción en los pasajes atribuidos a Bruto (D. 9, 2, 27, 22) y a Quinto Mucio (D. 9, 2, 39), pues mientras Bruto exige una calificación de rumpere y por eso habla de quasi rumpere, en Quinto Mucio el aborto involuntario debido al golpe representa un simple caso de rumpere, aunque luego agrega: "Pomponius may not be reporting Quintus' exact words and it is posible that the authentic versión of the decision was expressed in terms of a quasi rumpere" ${ }^{\prime 40}$.

En suma, como señala Valditara, la acción comprendida en el capítulo tercero de la ley no sólo comprendía las hipótesis en que la cosa fuera quemada (urere) o partida (frangere); sino que, en virtud de la equivalencia entre ruptus y corruptus, comprendía los casos en que el objeto era desgarrado, aplastado, derramado y de cualquier modo arruinado, estropeado, destruido o deteriorado ${ }^{41}$. Un buen ejemplo de esta interpretación se encuentra en el D. 9, 2, 27,17: "Rupisse eum utique accipiemus, qui vulneraverit, vel virgis vel loris vel pugnis cecidit, vel telo vel quo alio, ut scinderet alicui corpus, vel tumorem fecerit, si tita demum, si damnum iniuria datum est: ceterum si nullo servum pretio viliorem deterioremve fecerit, Aquilia cessat iniuria rumque erit agendum dumtaxat: Aquilia enim eas ruptiones, quae damna dant, persequitur. Ergo etsi pretio quidem non sit deteriorservus factus, veru sumptus in salutem eius et sanitatem facti sunt, in haec mihi videri damnum datum: atque ideoque lege Aquilia agi posse". ("Entendemos también que corrompió el que hubiese herido con varas o correas, o con los puños o con una espada o con cualquier otra cosa, de modo que cortara el cuerpo a alguien o le hubiese hecho un tumor, pero sólo si le causó un daño injusto. Si no hubiese devaluado o hecho más inútil al esclavo, cesa la Aquilia y sólo habrá de demandarse por injurias, porque la Aquilia persigue aquellos quebrantamientos que causan daño. Por consiguiente, aunque el esclavo no haya sido devaluado, pero se hicieron gastos en su curación y salud, en esto me parece que causó daño y, en consecuencia, puede demandarse por la ley Aquilia'" ${ }^{42}$.

con derecho, ni debe tratarla de otro modo que si fuera suya como arriba indicamos, sino que debe ahuyentarla sin daño o avisar al dueño que recoja lo suyo").

${ }^{40}$ MarcComarck, "Aquilian Studies", cit. nota n. 16, p. 4. Sobre esta cuestión, coincide, ZImmerman, The law, cit. nota n. 11, p. 984, quien indica que la expresión quasi corrumpere nace en aquellos casos en los que si bien es cierto se infringe un daño, un menoscabo sobre la cosa o bien o sujeto (esclavo), éste se mantiene en su conjunto, como precisamente ocurre en el aborto, en el que el daño consiste en la expulsión prematura del neonato, pero el cuerpo de la víctima permanece, en principio, intacto.

${ }^{41}$ Valditara, "Damnum iniuria", cit. nota n. 5, p. 849.

${ }^{42}$ Por lo demás, de manera similar lo expresa el propio Gayo en el pasaje referido al capítulo tercero, en 3, 217: "Si quid enim ustum aut ruptum aut fractum <fuerit>, actio hoc capite constituitur, quamquam potuerit sola rupti apellatio in omnes istas causas sufficere; ruptum <enim intellegitur, quod quoquo modo corruptum > est; unde non solum usta (aut rupta) aut fracta, sed etiam scissa et collisa et effusa et quoquo modo uitiata aut perempta atque deteriora facta hoc uerbo continentur" ( "Hay pues, acción 
Más allá fueron los juristas cuando extendieron el ámbito de aplicación de la ley para incorporar los casos de pérdidas de las cosas para el propietario, aun cuando éstas no se hubiesen destruido o deteriorado materialmente. Se trataba de situaciones, a diferencia de las anteriores, en las que no podía hablarse técnicamente de un daño físico inferido al propietario ${ }^{43}$. Dos textos son bastantes ilustrativos de esta tendencia. En el primero, de Alfeno, en D. 19, 5, 23: "Duo secundum Tiberium cum ambularent, alter eorum et qui secum ambulabat rogatus anulum ostendit, ut respiceret: illi excidit anulus et Tiberim devolutus est respondit posse agi cum eo in factum actione" ("Cuando paseaban dos personas a orillas del Tíber, una de ellas le mostró su anillo a la otra, a ruegos de ésta, para que lo examinase. Caído allí el anillo, fue a parar al Tíber. Respondió que puede reclamarse contra

para el caso de que algo fuera quemado, roto o estropeado, aunque para todo ello basta con la denominación de "roto", ya que se entiende que dentro de lo roto está incluida cualquier cosa que fuera estropeada de otro modo. Por lo tanto, se incluyen dentro de esta palabra las cosas quemadas, rotas, partidas, golpeadas, derramadas, y todas las que hayan sido estropeadas, destruidas o deterioradas").

${ }^{43}$ Un interesante análisis sobre un problema semejante puede encontrarse en RODGER, Alan, "Labeo, Proculus and the Ones trat Got Away", LQR 88, 1972, pp. 402 y ss. Este autor básicamente se dedica al análisis del pasaje contenido en D. 9, 2, 29, 3, que trata el caso en el que se pierde una nave al haberse cortado las cuerdas del ancla a la que fue conducida, impelida por la fuerza del viento. No pone atención en el caso principal, en el cual se concede una acción directa para el caso de haber culpa de los marineros, sino en las eventuales pérdidas o menoscabos indirectos, en el sentido de no haber sido inmediatamente provocados por el dañante, pues también se indica en el pasaje que no puede otorgarse una acción directa por los peces que no se han pescado, al no ser posible hacer valoración de ellos. Según el autor, puede pensarse que en este tipo de daños, tanto Labeón y Próculo, probablemente, habrían acordado una actio in factum. Compara esta decisión, con la opinión de Ulpiano, en 29,5, de acuerdo con la cual, si se corta la amarra de la nave, debe otorgarse una acción por el hecho por la pérdida de la nave. También lo compara con otro caso, en D. 9, 2, 27, 35, en el que encontramos a un albañil que, en vez de arreglar la cisterna de vino, la estropea y, como consecuencia, se derrama el vino. Estos tres pasajes tienen una nota común, consistente en que la cosa dañada directamente produce la afectación indirecta de otra; los peces, en el primer texto; la nave, luego de cortar las cuerdas y, el vino, cuando se ha estropeado la cisterna, aunque reconoce que el caso de la pérdida de los peces se trata de un daño eventual. Para Rodger, estos supuestos muestran cómo los juristas clásicos podían permitirse adoptar y ampliar una interpretación rígida de los intereses, porque las acciones indirectas fueron consideradas suplemento de la acción directa. En los casos decididos por Ulpiano, Labeón y Próculo, los daños indirectos no podían ser cubiertos por una acción directa y, precisamente por ello, se concedían acciones in factum. Así, la actio in factum habría surgido para cubrir en general los daños indirectos. Cfr. con MACCORMACK, "Aquilian Studies", cit. nota n. 16, p. 50, quien señala que no debe ser asumido que Labeón negara una acción directa en tales casos, ni puede estar seguro de la distinción entre acción directa y actio in factum, dependiendo del tipo de pérdidas.

Albanese, "Studi", cit. nota n. 3, p. 69 se refiere a la decisión de Ulpiano en D. 9, 2, 29, 5, como ejemplo de otorgamiento de una actio in factum cuando el damnum podía ser calificado como non corpori. Según Albanese, la brevedad del pasaje no permite determinar con claridad la hipótesis prevista, es decir, si acaso la nave naufragó o materialmente fue destruida como consecuencia de la navegación sin tripulantes, por haberse desprendido las amarras o simplemente fue perdida por el propietario. La normal aplicación de la lex Aquilia, de otra parte, habría conducido al irrisorio resarcimiento de las amarras cortadas. Indica que en la primera hipótesis prevista, debía haber sido concedida una acción útil, dado que el perjuicio era causado non corpore; en cambio, en la segunda hipótesis, fallando la lesión material de la cosa, correspondía el otorgamiento de una actio in factum. 
él con la acción por el hecho" $)^{44}$. El segundo, de Sabino, en D. 9, 2, 27, 21, es bastante similar: "Si quis de manu mihi nummos excusserit, Sabinus existimat damni iniuriae ese actionem, si ita perierint ne ad aliquem pervenerint, puta si in flumen vel in mare vel in cloacam ceciderunt: quod si ad aliquem pervenerunt, ope consilio furtum factum agendum, quod et antiquis placuit, idem etiam in factum dari posse actionem ait" ("Si alguien me hubiese tirado las monedas de la mano, opina Sabino que hay acción de daño injusto si se hubieran perdido de modo que no llegasen a manos de nadie, por ejemplo si cayeron al río, al mar o a una cloaca; pero si fueron a parar a algún cómplice, hay que demandar por el hurto cometido, como ya estimaron procedente los antiguos. El mismo Sabino dice también que puede darse una acción por el hecho").

Ambos textos presentan, sin duda alguna, una clara contradicción. Mientras en el primero se otorga una actio in factum, en el segundo Sabino concede la lex Aquilia, para el caso de las monedas arrojadas al río, al mar o a una cloaca. Con todo, la última parte del texto de Sabino es, como explica MacCormack, de difícil reconstrucción, pues si existe un cómplice y, por tanto, la intención de apoderarse de la cosa, se otorga la acción de hurto, mientras que la enigmática última frase, indica que Sabino también otorga una actio in factum ${ }^{45}$.

Como no pueden otorgarse ambas conjuntamente, tenemos tres acciones posibles en juego, para tres supuestos distintos. En opinión de MacCormarck, con independencia de las dudas que existen en relación con la originalidad del texto y a pesar de las dificultades que encierra, pudo haberse otorgado la actio legis Aquiliae, en el caso de pérdida por una travesura y, una actio in factum, siempre que existiese una conducta negligente: "Did he allow the actio legis Aquiliae in the case of the prank, the actio in factum in the case of the careles act? Unfortunately one cannot do more tan raise the question". Más adelante, deja claro, no obstante, que sólo Sabino otorgó una acción directa en el caso de pérdida de objetos, equiparándolo con la destrucción de la cosa, pues en los restantes, sólo se concedió una actio in factum, como ampliación pretoria del verbo rumpere ${ }^{46}$.

\footnotetext{
${ }^{44}$ AlbANESE, "Studi", cit. nota n. 3, pp. 81-83, trata el caso dentro de aquellos pasajes clásicos que afirman que las acciones in factum fueron otorgadas en los supuestos de daños non corpore. En relación con el daño, señala Albanese que estamos frente a un supuesto de pérdida irreparable para el propietario, propiedad que no habría podido ser tutelada con algún remedio jurídico normal.

${ }^{45}$ ALBANESE, "Studi" cit., nota n. 3, pp. 50 y ss., entiende que en el pasaje se encuentra interpolado la concesión de la actio damni iniuriae. Relacionando este texto con Gayo 3, 202, Albanese estima que al fallar el damnum corpori, es decir, al no ser destruida directamente la cosa, los clásicos optaron por el otorgamiento de una actio in factum e, incluso, propone una nueva reconstrucción del texto de acuerdo con su tesis.

${ }^{46}$ MacCormack, "Aquilian Studies", cit. nota n. 16, pp. 31-32; 35. Como explica Floria Hidalgo, María Dolores, La casuística del furtum en la jurisprudencia romana, Dykinson, Madrid, 1991, pp. 100-101, se trata de dos textos relacionados, al punto que serían dos versiones del mismo caso: el original, sería expuesto por Alfeno, con sus particularidades, de los dos amigos que paseaban por la orilla del Tíber, mientras que la versión de Sabino o de Ulpiano es una posterior extensión del supuesto, con el objeto
} 
Por eso, algunos otros textos parecen confirmar la posición de Alfeno. Por ejemplo, Labeón tiene dos decisiones en el mismo sentido. La primera se encuentra en D. 47, 2, 50, 4: "Cum eo qui pannum rubrum ostendit fugavitque pecus, ut in fures incideret, si quidem dolo malo fecit, furti actio est: sed et si non furti faciendi causa hoc fecit, non debet impunitus ese lusus tam perniciosus: ideirco Labeo scribit in factum dandam actionem" "Hay la acción de hurto contra el que presenta un paño rojo y pone en fuga el ganado, de modo que caiga en poder de los ladrones, si verdaderamente lo hizo con dolo malo; pero aunque esto no lo haya hecho para que se cometa hurto, no debe quedar impune juego tan pernicioso; y por eso escribe Labeón, que se ha de dar la acción por el hecho" ${ }^{47}$.

de hacerlo más general. Agrega que en estos pasajes puede verse una innovación en relación con los juristas anteriores, por cuanto frente al caso de pérdida según las características del caso, se decide otorgar una actio in factum, en vez de una actio furti, como lo habían hecho los juristas anteriores. En suma, la autora clasifica de esta manera el caso de las monedas o del anillo que se tira de la mano de otro: a) por los veteres, para aplicar la actio furti; b) en una versión limitada al anillo que se cae al Tíber, para conceder la actio in factum ad exemplu legis Aquiliae, siendo el autor de esta innovación probablemente Servio Sulpicio Rufo, según la referencia de Alfeno Varo; c) en una redacción más general y abstracta, de las monedas que alguien tira de la mano de otro, Sabino distingue si el dinero se pierde definitivamente, en cuyo caso concede la actio in factum, del que va a parar a las manos de otros, en el que se aplica la actio furti, siguiendo con ello un criterio ecléctico, y d) algunos juristas como Gayo y Ulpiano, utilizaron el caso como un ejemplo de complicidad, en la versión de que lanza las cosas para que otro se apropie de ellas (ello según el pasaje de Ulpiano en D. 47, 2, 52, 13). Finalmente, sobre las dudas que plantea la autenticidad del pasaje atribuido a Sabino, puede consultarse a HuveLIN, P., Ètudes sur furtum. Dans le très ancien Droit romain, L'erma di Bretschneider, Roma, 1968, p. 393. Un caso similar es citado por VALIÑO, Acciones útiles, cit. nota n. 3, pp. 335-336. Se trata de un pasaje atribuido a Ulpiano, en D. 47, 8, 2, 20: "Si publicanus pecus meum abduxerit, dum putat contra legem vectigalis aliquid a me factum: quamvis erraverit, agi tamen cum eo vi bonorum raptorum non posse Labeo ait: sane dolo caret: si tamen ideo inclusit, ne pascatur et ut fame periret, etiam utili lege Aquilia" ("Si un publicano me hubiere quitado mi ganado, creyendo que por mí se hizo algo contra la ley tributaria, aunque hubiere errado dice Labeón, que no se puede, sin embargo, ejercitar contra él la acción de bienes arrebatados con violencia; ciertamente está exento de dolo, pero si lo encerró, para que no pastara, y para que pereciere de hambre, estará sujeto también a la acción útil de la ley Aquilia”). De modo que si un publicano se lleva erróneamente el ganado de un propietario, creyendo que había realizado algo contra la ley del censo, no puede otorgarse la actio vi raptorum, pero en cambio, según Labeón, si ha encerrado al ganado, de tal modo que no pueda salir en busca de alimentos, procede contra él la acción de la lex Aquilia. Como comenta VALINO, Acciones útiles, cit. nota n. 3, p. 338, en el texto: "Ulpiano estaba comentando aquí el edicto de la actio vi bonorum raptorum y en el fragmento correspondiente traía a colación el criterio de Labeón en el sentido de que esta acción presupone el dolo, y si no se da éste, no procede la acción".

${ }^{47}$ Siguiendo a FloriA, La casuística, cit. nota n. 46, p. 87, no puede dudarse que en este caso se otorgó originariamente en el texto la actio in factum, pues era un criterio adoptado anteriormente por los juristas; además, indica que el pasaje siguiente de Gayo, en D. 47, 2, 51, confirma la regla: "nam et si praecipitata sint pecora, utilis actio damni iniriae, quasi ex lege Aquilia dabitur" ("porque también si el ganado se hubiere echado por un precipicio, se dará como por la ley Aquilia la acción útil de daño con injuria"). Cfr. con AlbANESE, "Studi", cit. nota n. 3, pp. 45-46, quien se refiere a este pasaje como un texto estrictamente conectado con el pasaje anterior, es decir, la decisión de Gayo en D. 47, 2, 51, en el que el daño es non corpore y, en consecuencia, debía haber sido otorgada una actio utilis y no una in factum. Con todo, este pasaje del ganado espantado con un paño rojo es considerado por el autor como sustancialmente genuino. 
En cuanto a la segunda, es de D. 4, 3, 7, 7: "idem Labeo quaerit, si compeditum servum meum ut fugeret solveres, an de dolo actio danda sit? Et ait Quitus apud eum notans: si non misericordia ductus fecisti, furtu teneris: si misericordia, in facxtum actionem dari debere" ("Pregunta el mismo Labeón: si hubieses desatado, para que huyese, a un esclavo mío que tenía preso, ¿debe darse contra ti la acción de dolo? Y dice Quinto (Cervidio Escévola), comentando a Labeón, que si no lo hicisteis por misericordia, quedarás obligado por la acción de hurto, y si lo hiciste por misericordia, debe darse la acción por el hecho' $)^{48}$.

Según MacCormarck, los textos citados pueden resumir el pensamiento de los juristas de la siguiente manera: si hubo intención de apoderarse de la cosa ajena, se otorgaba una actio furti. En cambio, si no había intención de apropiarse de la cosa, pero se causaba daño al propietario por una travesura o juego, se otorgaba una actio in factum, como en los supuestos de las monedas arrojadas al Tíber o el ganado espantado con el paño rojo. Si, por el contrario, había intención de causar daño al propietario, los juristas se dividen: a veces otorgaron la actio in factum, como en el mismo caso de las monedas arrojadas al Tíber o, incluso, la actio doli ${ }^{49}$.

\footnotetext{
${ }^{48}$ Sobre este caso indica Floria, La casuística, cit. nota n. 46, pp. 80-82, que cuando el causante ha obrado por misericordia o por motivos altruistas, procede la acción por el hecho ad exemplum lege Aquilia, toda vez que no concurre dolo. Formaría parte de un grupo de casos bastante similares referidos al hurto analizados por la autora.

${ }^{49}$ MacCormack, "Aquilian Studies", cit. nota n. 16, p. 36. En otro trabajo suyo, MacCormack, "Juristic interpretation", cit. nota n. 13, p. 272, analizando el caso decidido por Labeón, en D. 47, 2, 50, 4, llega a una conclusión similar. Hay más textos que permiten sostener esta conclusión. Por ejemplo, Sabino en D. 19, 5, 14: "Qui servandarum mercium suarum causa alienas merces in mare proiecit, nulla tenetur actione: sed sine causa id fecisset, in factum, si dolo, de dolo tenetur" " "El que con finalidad de salvar sus mercancías lanzó al mar mercancías ajenas, no está obligado por ninguna acción; pero si lo hiciese sin justa causa estará obligado mediante la acción por el hecho; y si lo hiciese con dolo, por la acción de dolo"). El pasaje es bastante claro: si hay justa causa no se otorga acción, por cuanto opera una causa justificante. Por el contrario - donde puede apreciarse una clara conexión entre la culpa y la iniuria- si no hay causa o justificación, aunque no se trate propiamente de una travesura, la acción otorgada era la in factum; y si, por el contrario, había intención de causar pérdida al propietario, se otorgaba una acción de dolo.

Estas ideas de MacCormack pueden conectarse con los argumentos de PUGSLEY, "On the lex", cit. nota n. 5, pp. 10 y ss., quien sostiene que especialmente los juristas republicanos diferenciaron entre acciones pretorias o in factum y acciones directas, de acuerdo con la intencionalidad. Así, en el caso de haber intención de dañar o una conducta dolosa, se otorgó la acción directa; en cambio, si había habido sólo culpa o negligencia, dado que ésta no se encontraba originariamente en los textos, la protección era dada a través de acciones in factum. El primer autor en introducir este punto de vista, parece haber sido Quinto Mucio, como queda claro en el caso del D. 9, 2, 31 pr., quien con independencia del lugar donde han caído las ramas cortadas, utiliza la culpa como mecanismo de imputación.

Una lectura distinta es la que ofrece AlBANESE, "Studi", cit. nota n. 3, pp. 89-92, quien sostiene que en los párrafos siguientes al tercero, fueron todos casos en los cuales Labeón se inclinaba por la concesión de una actio doli, en la duda de la concurrencia de otra acción. Explica Albanese que, originariamente la noción de furto había comprendido todas las hipótesis de comportamiento doloso que concluyera con la pérdida para el propietario, mientras que la lex Aquilia requería la destrucción material del bien. La extensión del ámbito de aplicación de la lex a los supuestos de menoscabos non corpore, coincidió con la exigencia de lucro en el furtum.
} 
La síntesis de esta evolución, como hemos visto en otro lugar, queda absolutamente confirmada en el pasaje de Ulpiano, D, 9, 2, 27, 13: "Inquit lex "ruperit" rupisse verbum fere omnes veteres sic intellexerunt "corrumperit" ("La ley dice 'hubiere roto'. La palabra haber roto la entendieron casi todos los antiguos como haber corrompido" $)^{50}$.

Por otra parte, al igual como ocurrió con el verbo occidere, en la interpretación de los verbos del tercer capítulo, se exigía igualmente una causalidad física directa e inmediata (damnum corpori corpore), es decir, una acción material desplegada directamente sobre el objeto dañado. Nuevamente se produce una ampliación del ámbito de aplicación de la ley, para incorporar los supuestos en los que no existía una causalidad directa ni una acción directa sobre la cosa que resultaba destruida o bien, la actuación del agente dañoso era meramente omisiva. Así ocurre, por ejemplo, en el texto de Gayo 3,20251.

Sin embargo y para concluir el análisis de esta cuestión, la extensión del tercer capítulo de la ley por la vía de corrumpere tenía también limitaciones. Como explica Zimmermann, la aplicación del verbo estaba limitada a los casos en los que el objeto no habría sufrido deterioro y pone el ejemplo del pasaje de

${ }^{50}$ Cannata, "Il terzo capo", cit. nota n. 5, p. 140. En verdad, como indica MarcComack, "Aquilian Studies", cit. nota n. 16, pp. 4; 9, sólo pueden encontrarse dos decisiones específicas sobre el verbo rumpere en el Digesto -los ya citados pasajes atribuidos a Bruto y Quinto Mucio-, sin embargo, nos encontramos con esta declaración de Ulpiano, en la que sostiene que casi todos los veteres entendieron rumpere como corrumpere. Agrega: "It is difficult to know what inferences may be drawn from this statements. There is no record of any Republican jurist framing a decision in terms of corrumpere". Lo que está claro es que dicha declaración parece haber sido tomada de Celso, a quien el autor adjudica absoluto protagonismo en el desarrollo de la expresión corrumpere. Luego señala que de la declaración de Ulpiano pueden inferirse dos posiciones sobre la interpretación de corrumpere. Mientras la mayoría de los juristas incluyó rumpere en corrumpere, otros restringieron la extensión rumpere a situaciones que podían se clasificadas como quasi rumpere, como ocurre en el pasaje de Bruto. Además, agrega que algunos juristas pensaban que Celso había ido muy lejos al interpretar corrumpere de manera tan amplia, pero que resulta incierto que hubiesen objetado sus sentencias, tal como hemos visto a propósito del pasaje del D. 9, 2, 27, 16. Para estos juristas, la interpretación amplia de corrumpere representaba un peligro, por lo que intentaron restringir el alcance de una interpretación amplia, por ejemplo: si rumpere debía ser entendido como corrumpere, no hubiese sido necesario incluir los verbos frangere y urere. Cita ejemplos en que Juliano entiende de manera diversa corrumpere a los supuestos proporcionados por Celso, contenido en D. 9, 2, 42.

${ }^{51}$ Reza el párrafo: "Interdum furti tenetur qui ipse furtum non fecerit, qualis est cuius ope consilio furtum factum est. In quo numero est qui nummos tibi excussit ut eos alius subriperet, vel obstitit tibi ut alius subriperet, aut oves aut boves tuas fugavit ut alius eas exciperet; ed hoc veteres scripserunt de eo qui panno rubro fugavit armentum. Sed si quid per lasciviam et non data opera, ut furtum commtteretur, factum sit, videbimus an utilis actio dari debeat, cum per legemn Aquiliam quae de damno lata est etiam culpa puniatur" ("Igualmente, está vinculado por la acción del hurto, quien no comete hurto personalmente, como es aquel por cuya ayuda o consejo se cometió el hurto. Entre éstos se incluye quien te sacude tu dinero para que otro te lo robe, o te distrae para que otro te robe, o hizo huir tus ovejas o bueyes para que otros los capturaran. Y esto dijeron los antiguos de aquél que espantó el rebaño con una tela roja. Pero si hizo esto por diversión y no a propósito para que se cometiera hurto, acaso procediera dar una acción útil, puesto que la ley Aquilia prevé el daño causado con culpa"). 
Viviano, informado por Ulpiano en D. 9, 2, 27, 28: "Si alguien hubiese castrado a un niño esclavo y lo hubiese hecho así más valioso, escribe Viviano que no se aplica la ley Aquilia, sino que habrá que demandarse por injurias, o el cuádruplo por el edicto de los ediles". En segundo lugar, no existiría corrumpere si el objeto en cuestión era cambiado en alguna forma ${ }^{52}$.

\section{CONCLUSIOnes}

La lex Aquilia nació como un mecanismo de protección en favor del propietario, quien en caso contrario se veía desprotegido en las situaciones de destrucción o deterioro de la cosa, pues la rei vindicatio exigía la existencia actual de ésta y la condictio, por su naturaleza, presuponía el tránsito o traspaso de la posesión material del demandado, a objeto de fundar la obligación de restitución. La lex Aquilia, por tanto, establecía la obligación genérica nacida de delito, con la idea de hacer surgir un crédito equivalente al valor de la cosa destruida en favor del propietario. Y esta cuestión tiene importancia a la hora de precisar la naturaleza de la acción que emanaba de ley.

Cannata señala que en los capítulos primero y tercero de la ley el sujeto protegido era el propietario y, por esto, la actio legis aquiliae entró en el edicto pretorio entre los remedios que tutelan la propiedad, aunque hasta esta cuestión es discutida, pues algunos han sostenido que no se protegía exclusivamente al propietario ${ }^{53}$. Es por ello que, como afirma el propio Cannata en otro trabajo suyo, la ley sólo contempló, en su hipótesis inicial de regulación, la destrucción de la cosa, sin pretensión de regular íntegramente la materia de los daños ${ }^{54}$.

${ }^{52}$ ZimMERMAN, The law, cit. nota n. 11, p. 986. En apoyo de esta segunda limitación, cita el pasaje de Celso, en D. 9, 2, 27, 14, el cual, en la parte que interesa al autor indica: "nam alia quaedam species damni est ipsum quid corrumpere et mutare, ut lex Aquilia locum habeat, alia nulla ipsius mutatione applicare aliud, cuius molesta separatio sit" ("Y no es lo mismo corromper y cambiar algo esencialmente de tal modo que tenga lugar la ley Aquilia que, si no altera la cosa esencialmente añadir algo cuya separación resulta gravosa"). No obstante, anota el autor una decisión completamente distinta en Ulpiano, considerando un caso similar como quasi corrumpere, en D. 9, 2, 27, 20: "Igualmente, si alguien mezcló arena un otra cosa con trigo, de modo que la separación sea difícil, podrá demandarse como por haber corrompido". Este caso lo considera cercano o emparentado con aquellos en los que el propietario era privado de un específico ítem o parte de su propiedad, pero en estricto rigor dicha parte de su propiedad no se había destruido, como el caso de las monedas arrojadas de la mano, que antes hemos analizado.

${ }^{53}$ Cannata, Sul problema, cit. nota n. 5, p. 42. En el mismo sentido Valditara, "Damnum iniuria", cit. nota n. 5, p. 879.

${ }^{54}$ CANNATA, "Il terzo capo", cit. nota. n. 5, p. 130. Debe confrontarse esta posición, por ejemplo, con la de BIGNARDI, "Frangere e rumpere", cit. nota n. 9, p. 30, quien sostiene que si bien es cierto la ley nace como mecanismo de protección del propietario, no puede ser descartada su intrínseca naturaleza penal, pues su objeto fue sobre todo reprimir conductas que, a causa de su naturaleza, habían destruido bienes. Agrega que dicho papel central queda claro con la estructura de los capítulos primero y tercero: "Sia nel primo sia nel terzo capitolo della legge si riscontra il seguente schema: dapprima si indica la cosa sulla quale avviene la lesione, poi il comportamento in relazione al quale si determina l'evento 
Desde luego, la visión contraria la ofrece Daube, para quien precisamente el mecanismo de protección radica en haber establecido un sistema de valoración de las pérdidas sufridas por el propietario ${ }^{55}$.

Ahora bien, es claro que la ley nace con esta óptica, pero sucesivamente fue transformando su carácter, no sólo porque se otorgaron acciones útiles en favor de sujetos que no eran propietarios, sino porque las víctimas -si seguimos la línea tradicional- pudieron recurrir en contra de sujetos que no habían provocado directa y materialmente el perjuicio o aun cuando la cosa no había resultado destruida, sino que sólo había disminuido su valor. En todo caso, nada de ello es seguro, pues permanecen las discusiones sobre casi todos los aspectos de la ley, aun incluso fuera del radio del capítulo tercero, pues, cuando nos enfrentamos al principio corpore corpori, que habría articulado la ley, en la lectura tradicional se trata de un componente originario de la ley, aunque, para otros, se desarrolló en la Edad media, comprendiendo la ley las omisiones desde un principio, o bien afirmando que fue un producto de la jurisprudencia clásica, tendiente a limitar los alcances de la ley.

En este trabajo, se han querido reflejar dichas distintas aproximaciones, pero al margen de ello, hemos analizado cómo la jurisprudencia introdujo una segura y paulatina ampliación de los alcances de la lex Aquilia, traduciendo ésta en un mecanismo flexible para atribuir responsabilidad, sin que sus figuras perdieran el carácter típico y, en consecuencia, sin alcanzar una cláusula general de responsabilidad ${ }^{56}$, que obedeció a otros postulados filosóficos y sólo fue alcanzada con el iusnaturalismo racionalista.

lesivo, e infine la sanzione. In entrambi i capitoli il sudetto schema serve a sottolineare, anche strutturalmente, la "centralità" della condotta quale fattore determinante l'intervento legislative. La struttura del testo corresponde alle finalità del plebiscito, volto innanzitutto a reprimiré l'atto illecito e solo secondariamente, forse, a provvedere in merito allo squilibrio económico da quello determinato". En este sentido, Valditara, "Damnum iniuria", cit. nota n. 5, pp. 840, 878 y ss., indica que precisamente el carácter penal de la ley justifica la falta de una necesaria correlación entre el daño causado y la entidad de la liquidación, que podía ser mayor que el perjuicio sufrido, debido a la presencia de la palabra plurimi, estableciéndose una pena fija; además, en sus orígenes la ley se preocupaba de proteger al propietario y, por lo mismo, el daño económico puesto en consideración decía relación sólo con la pérdida del bien o con el valor de disminución causado por el ilícito; se liquidaba, por tanto, sólo el corpus dañado o destruido y sólo sucesivamente fue contemplándose en la valoración del quantum el patrimonio del dañado y los intereses afectados de éste.

${ }^{55}$ Daube, "On the third", cit. nota n. 5, pp. 256-257.

${ }^{56}$ Esta cuestión ha sido puesta en evidencia por ValditaRA, "Damnum iniuria", cit. nota n. 5, p. 872, señalando que la ley pasó de ser un instrumento de protección de la propiedad a uno más amplio de protección del patrimonio, especialmente luego que se comenzaran a otorgar acciones a sujetos distintos del dueño, como el poseedor o el usufructuario. CANNATA, "Il terzo capo", cit. nota n. 5, pp. 120, 130-132, agrega que después de la dictación de una ley que regulaba el acaecimiento del damnum provocado con iniuria, era intolerable que esta protección se produjera con el otorgamiento de acciones in factum en relación a otros delitos. Para De RoBerTIS, Francesco, Damnum inuiria datum. "La responsabilità extra-contrattuale nel diritto romano; con particolare riguardo alla lex Aquilia de 


\section{BibLiOGRAFíA}

Aedo Barrena, Cristián, "Los requisitos de la lex Aquilia, con especial referencia al daño. Lecturas desde las distintas teorías del capítulo tercero", lus et Praxis, Año 15, № 1, 2009.

"La actio legis aquiliae: concepto, características y desarrollo decretal posterior. Lecturas desde el capítulo tercero", Revista de Derecho Universidad Católica del Norte 16, 1, 2009.

Albanese, Bernardo, "Studi sulla legge Aquilia", AUPA 21, 1950.

ANKUM, Hans, "Quanta ea res erit in diebus XXX proximis dans le troisième chapitre de la lex Aquilia: un fantasme florentin", en Etiennne Bravasa, Claude Emeri; Seurin, Jean Louis (Edits.), Mélanges en Hommage a Jacques Ellul. Religión, société et politique, PUF, París, 1983.

Arangio Ruiz, Vicenzo, Instituciones de Derecho Romano, Traducción castellana de la $10^{a}$ Edición italiana de Caramés Ferro, José, reimpresión de la $1^{\mathrm{a}}$ Edición, Depalma, Buenos Aires, 1986.

Barton, J.L, "The Lex Aquilia and Decretal Actions", en Watson, Alan (Edit.), Daube Noster. Essays in Legal History for David Daube, Scottish Academic Press, Edimburgo, 1974.

Bettı, Emilio, Istituzioni di Diritto Romano, Cedam, Padova, 1962.

BignaRDI, Alessandra, "Frangere e rumpere nel lessico normativo en ella interpretatio prudentium", en Nozione, formazione e interpretazione del Diritto. Dall'età romana alle esperienze moderne. Ricerche dedicate al profesor Filippo Gallo, Jovene Editore, Nápoles, 1997.

Bıondı, Biondo, Istituzioni di Diritto Romano, $4^{\text {a }}$ Edición, Giuffrè, Milán, 1965.

Bravo Bosch, María José, "Algunas consideraciones en torno a la Lex Aquilia", en Murillo Villar, Alfonso (Coord.), Estudios de Derecho Romano en memoria de Benito María Reimundo Yanes, Ediciones Universidad de Burgos, Burgos, 2000.

Cannata, Carlo Augusto, Sul problema della responsabilità nel Diritto Privato Romano, Libreria Editriche Torre Catania, Catania, 1996 "Il terzo capo dalla "Lex Aquilia", BIDR 98-99, 1995-1996.

damno", vol. II, Caccuci Editore, Bari, 2002, pp. 161-165, en los inicios del principado se va a producir una radical inversión de rumbo respecto a la disciplina de la actio legis Aquiliae, de rei persecutoria a penal, agregando que tal inversión caracteriza el desarrollo de la materia de Justiniano en adelante. Agrega: "Dal carattere penale, proprio ormai della azione aquiliana, no mancò di acompagnarsi la non imputabilità di chi non avese avuto alcuna volontà di danneggiare altri o che comunque non fosse stato cosciente delle conseguenze del suo operare (...) La caratterizzazione penale del damnum iniuria datum informo di sè tutto il successivo sviluppo della materia". 
Cardascia, G., "La portée primitive de la Loi Aquilia", Watson, Alan (Edit.), Daube Noster. Essays in legal history for David Daube, Scotish Academic Press, Edimburgo, 1974.

CAstresana, Amelia, Nuevas lecturas de la responsabilidad aquiliana, Ediciones Universidad de Salamanca, Salamanca, 2001.

Corbino, Alessandro, Il danno qualificato e la lex Aquilia, Cedam, Milán, 2005.

DAUBE, David, "On the third chapter of the lex Aquilia", LQR 52, 1936. "On the use of the term damnum", en Studi in onore di Siro Solazzi, Casa Editriche Eugenio Jovene, Nápoles, 1948. Roman Private law. Linguistic, social and philosophical aspects, Edinburg University Press, Edimburgo, 1969.

De Robertis, Francesco, "Damnum inuiria datum. La responsabilità extracontrattuale nel diritto romano; con particolare riguardo alla lex Aquilia de damno", Caccuci Editore, Bari, 2002.

D’Ors, Álvaro; Hernández Tejeiro, F.; Fuenteseca, P.; García Garrido, M.; Burillo, J., El Digesto de Justiniano, Aranzadi, Pamplona, 1988.

Floria Hidalgo, María Dolores, La casuística del furtum en la jurisprudencia romana, Dykinson, Madrid, 1991.

Hernández Tejeiro, Francisco (Coord.); Abellan Velasco, Manuel; Arias Bonet, Juan Antonio; Iglesias Redondo, Juan; Roset Esteve, Jaime, Instituciones de Gayo, Edición bilingüe, Civitas, Madrid, 1985.

Huvelin, P., Ėtudes sur furtum. Dans le très ancien Droit romain, L'erma di Bretschneider, Roma, 1968.

Jolowicz, H.F., "The original scope of the lex Aquilia and the question of damages", LQR 38, 1922.

KeLLY, John, "The meaning of the lex Aquilia", LQR 80, 1964.

, "Further reflections on the lex Aquilia", en Studi in onore di Edoardo Volterra, Giuffrè, Milán, 1971.

MacCormack, Geoffrey, "On the third chapter of the lex Aquilia", The Irish Jurist 5, 1970.

, "Aquilian culpa", en Watson, Alan (Edit.), Daube Noster. Essays in legal history for David Daube, Scotish Academic Press, Edinburgo, 1974. , "Aquilian Studies", SDHI 41, 1975.

"Juristic interpretation of the lex Aquilia", en Studi in onore di Cesare Sanfilippo, Giuffrè, Milán, 1982.

Martínez SarRIón, Ángel, Las raíces romanas de la responsabilidad por culpa, Bosch, Barcelona, 1993.

Mommsen, Theodorus; Krueger, Paulus, Corpus luris Civilis. Volumen Primum. Instituciones. Digesta, Weidmann, Hildesheim, 1988. 
NúÑez PAZ, María Isabel, La responsabilidad de los médicos en Derecho romano, Gráficas Apel, Gijón, 1996.

Pringsheim, F., "The origin of the Lex Aquilia", en Mélanges Henry Lévy-Bruhl, Institut du Droit Romain de l'Université de Paris, París, 1959.

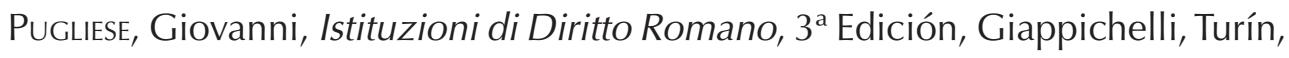
1991.

Pugsley, David, "On the lex Aquilia and culpa", TR 50, 1982.

Rodger, Alan, "Labeo, Proculus and the Ones trat Got Away", LQR 88, 1972.

SHIPANI, Sandro, Responsabilità "Ex lege Aquilia". Criteri di imputazione e problema della "culpa", Giappichelli, Turín, 1969.

Valditara, Giuseppe, "Damnum iniuria datum", en Paricio, Javier (Coord.), Derecho romano de obligaciones. Homenaje al profesor José Luis Murga Gener, Editorial Centro de Estudios Ramón Areces, Madrid, 1994.

ValiÑo, Emilio, Acciones útiles, Ediciones Universidad de Navarra, Pamplona, 1974.

Van Warmelo, Paul, "A propos de la loi Aquilia", RIDA 27, 1980.

Watson, Alan, Roman Private Law around 200 BC, Edinburgh University Press, s.d.

, The law of obligations in the later Roman republic, Clarendon Press, Londrés, 1965.

, "D. 7.1.13.2 (Ulpian 18 ad Sab.), the lex Aquilia and decretal action", lura 17, 1966.

"Narrow, rigid and literal interpretation in the later Roman Republic", TR 37, 1969.

, "The original meanings of pauperies", RIDA 17, 1970.

Zıııото, Paola, L'imputazione del danno aquiliano. Tra iniuria e damnum corpore datum, Cedam, Padova, 2000.

Zimmermann, Reinhard, The Law of Obligations Roman Foundations of the vilian tradition, Clarendon Paperbacks, OxFord, 1996. 